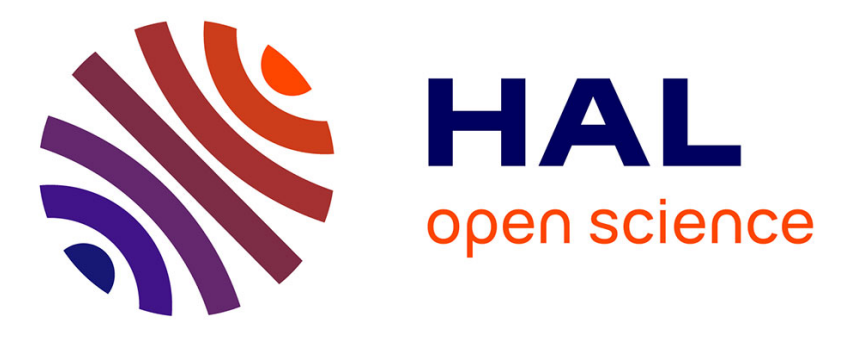

\title{
Linking above- and belowground phenology of hybrid walnut growing along a climatic gradient in temperate agroforestry systems
}

Awaz Mohamed, Alexia Stokes, Zhun Mao, Christophe Jourdan, Sylvie

Sabatier, Francois Pailler, Stéphane Fourtier, Lydie Dufour, Yogan Monnier

\section{To cite this version:}

Awaz Mohamed, Alexia Stokes, Zhun Mao, Christophe Jourdan, Sylvie Sabatier, et al.. Linking above- and belowground phenology of hybrid walnut growing along a climatic gradient in temperate agroforestry systems. Plant and Soil, 2018, 424 (1-2), pp.103-122. 10.1007/s11104-017-3417-4 . hal01837395

\section{HAL Id: hal-01837395 \\ https://hal.science/hal-01837395}

Submitted on 26 May 2020

HAL is a multi-disciplinary open access archive for the deposit and dissemination of scientific research documents, whether they are published or not. The documents may come from teaching and research institutions in France or abroad, or from public or private research centers.
L'archive ouverte pluridisciplinaire HAL, est destinée au dépôt et à la diffusion de documents scientifiques de niveau recherche, publiés ou non, émanant des établissements d'enseignement et de recherche français ou étrangers, des laboratoires publics ou privés. 


\section{Plant and Soil}

\section{Above and belowground phenological relationships in hybrid walnut growing along a climatic gradient \\ --Manuscript Draft--}

\begin{tabular}{|c|c|c|}
\hline \multicolumn{3}{|l|}{ Manuscript Number: } \\
\hline Full Title: & \multicolumn{2}{|c|}{$\begin{array}{l}\text { Above and belowground phenological relationships in hybrid walnut growing along a } \\
\text { climatic gradient }\end{array}$} \\
\hline Article Type: & \multicolumn{2}{|c|}{ Special Issue S71 - Root Ecology } \\
\hline Keywords: & \multicolumn{2}{|c|}{ Agroforestry; rhizotron; root elongation; initiation; mortality; longevity } \\
\hline Corresponding Author: & \multicolumn{2}{|c|}{$\begin{array}{l}\text { Alexia Stokes } \\
\text { INRA } \\
\text { MONTPELLIER CEDEX } 5 \text {, FRANCE }\end{array}$} \\
\hline \multicolumn{3}{|l|}{$\begin{array}{l}\text { Corresponding Author Secondary } \\
\text { Information: }\end{array}$} \\
\hline Corresponding Author's Institution: & \multicolumn{2}{|l|}{ INRA } \\
\hline \multicolumn{3}{|l|}{$\begin{array}{l}\text { Corresponding Author's Secondary } \\
\text { Institution: }\end{array}$} \\
\hline First Author: & \multicolumn{2}{|l|}{ Awaz Mohamed } \\
\hline \multicolumn{3}{|l|}{ First Author Secondary Information: } \\
\hline \multirow[t]{9}{*}{ Order of Authors: } & \multicolumn{2}{|l|}{ Awaz Mohamed } \\
\hline & \multicolumn{2}{|l|}{ Alexia Stokes } \\
\hline & \multicolumn{2}{|l|}{ Zhun Mao } \\
\hline & \multicolumn{2}{|l|}{ Christophe Jourdan } \\
\hline & \multicolumn{2}{|l|}{ Sylvie-Annabel Sabatier } \\
\hline & \multicolumn{2}{|l|}{ François Pailler } \\
\hline & \multicolumn{2}{|l|}{ Stephane Fourtier } \\
\hline & \multicolumn{2}{|l|}{ Lydie Dufour } \\
\hline & \multicolumn{2}{|l|}{ Yogan Monnier } \\
\hline \multicolumn{3}{|c|}{ Order of Authors Secondary Information: } \\
\hline \multirow[t]{4}{*}{ Funding Information: } & Meta program INRA-AAFCC & Dr. Alexia Stokes \\
\hline & Campus France (FR) & Dr Awaz Mohamed \\
\hline & Kurdish Institute & Dr Awaz Mohamed \\
\hline & Fondation de France & Dr Yogan Monnier \\
\hline Abstract: & \multicolumn{2}{|c|}{$\begin{array}{l}\text { Background and Aims } \\
\text { Plant phenology is a sensitive indicator of plant response to climate change. } \\
\text { Observations of phenological events belowground for most ecosystems are difficult to } \\
\text { obtain and are less characterized than those aboveground. Very little is known about } \\
\text { the relationship between shoot and root phenology, especially in the field. We } \\
\text { examined the influence of environmental factors and root morphological traits on fine } \\
\text { root production and mortality in relation with shoot phenology in hybrid walnut trees } \\
\text { (Juglans sp. L.) growing in three different climates (oceanic, continental and } \\
\text { Mediterranean) along a latitudinal gradient in France. } \\
\text { Methods } \\
\text { Eight rhizotrons were installed at each site for } 21 \text { months to monitor tree root } \\
\text { dynamics. Root elongation rate (RER), root initiation quantity (RIQ) and root mortality }\end{array}$} \\
\hline
\end{tabular}


quantity (RMQ) were recorded frequently using a scanner and time-lapse camera. Leaf phenology, phenological phases and stem radial growth were also measured. Fine roots were classified into orders and 0-1 mm, 1-2 mm and 2-5 mm diameter classes and fine root longevity and risk of mortality were calculated per class of diameter at each site during different periods over the year.

Results

Root growth was not synchronous with leaf phenology in any climate or either year, but was synchronous with stem growth during the late growing season. A distinct bimodal pattern of root growth was observed during the aerial growing season but growth was negligible during the rest of the year. Maximal mean root elongation rates (RER) ranged from 2-5 $\mathrm{mm}$ during the late growing season (when leaves were still functioning), depending on climate. Mean RER was driven by soil temperature measured in the month preceding root growth in the oceanic climate site only. However, mean RER was significantly correlated with mean soil water potential measured in the month preceding growth at both Mediterranean (positive relationship) and oceanic (negative relationship) sites. Root diameter had no effect on RER. Mean RIQ was significantly higher at both continental and Mediterranean sites compared to the oceanic site. Soil temperature was a driver of mean RIQ during the late growing season at continental and Mediterranean sites only. Mean RMQ increased significantly with decreasing soil water potential during the late aerial growing season at the continental site only. Mean root longevity at the continental site was significantly greater than for roots at the oceanic and Mediterranean sites. Roots in the 0-1 mm and 1-2 $\mathrm{mm}$ diameter classes lived for significantly shorter periods compared to those in the $2-5 \mathrm{~mm}$ diameter class. First order roots lived longer than lateral roots at the Mediterranean site only and first order roots in the 0-1 mm diameter class had $44.5 \%$ less risk of mortality than that of lateral roots for the same class of diameter.

\section{Conclusions}

We conclude that factors driving root RER were not the same between climates. However, soil temperature was the best predictor of root initiation at all three sites, but drivers of root mortality remained largely undetermined.

\section{Suggested Reviewers:}

Dali Guo

Institute of Geographic Sciences and Natural Resources Research Chinese Academy of Sciences

guodl@igsnrr.ac.cn

Senior scientist in domain

Marie Loreto Contador

University of California San Diego

mlcontador@ucdavis.edu

Specialist in the domain

Louise Comas

US Department of Agriculture

Louise.Comas@ars.usda.gov

Specialist in the domain

Angelo Vitone

Universita degli Studi del Molise

angelo.vitone@entecra.it

Specialist of walnut shoot and root growth

Laura Radville

Pennsylvania State University Huck Institutes of the Life Sciences

lur150@psu.edu

Specialist of root phenology 


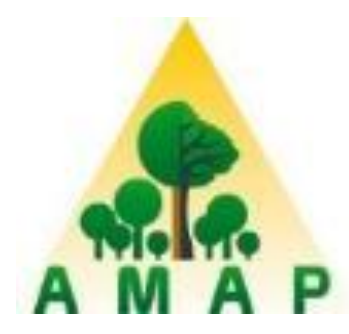

UMR AMAP, Mixed Research Unit

36/PS1, Bd de la Lironde

34398 Montpellier cedex 5, France

$19 / 4 / 2017$

Dear Hans,

We would like to submit the attached manuscript, entitled "Above and belowground phenological relationships in hybrid walnut growing along a climatic gradient" for consideration as a full paper in Plant and Soil (Special issue Root Ecology - EcoSummit 2016). All co-authors have agreed to the final version of the manuscript, which has not been submitted elsewhere.

Our think our manuscript is suitable for Plant and Soil because of the need for detailed data when aiming to understand, quantify and model fine root dynamics in relation to soil carbon sequestration and ecosystem functioning. We also require a better understanding of root system growth and phenology, especially in the natural soil environment.

Thank you for your consideration of our manuscript. Please do not hesitate to contact me if you require further information.

Yours sincerely

Alexia

Comment citer ce document 
1 Above and belowground phenological relationships in hybrid walnut

2 growing along a climatic gradient

3

4 Awaz Mohamed ${ }^{1}$, Alexia Stokes ${ }^{1 *}$, Zhun Mao $^{1}$, Christophe Jourdan $^{2}$, Sylvie Sabatier ${ }^{1}$,

$5 \quad$ François Pailler ${ }^{1}$, Stephane Fourtier ${ }^{1}$, Lydie Dufour $^{3}$, Yogan Monnier $^{1}$

$6 \quad{ }^{1}$ Umr Amap, Inra, Cnrs, Ird, Cirad, Université de Montpellier, Montpellier, France

$7 \quad{ }^{2}$ CIRAD, UMR Eco\&Sols (Ecologie Fonctionnelle \& Biogéochimie des Sols et des Agro-

8 écosystèmes), 2 place Viala, 34060 Montpellier cedex 2, France

$9 \quad{ }^{3}$ Umr System, Inra, 2 place Viala, 34060 Montpellier cedex 2, France

*Corresponding author

\section{Key words}

Agroforestry; rhizotron; root elongation; initiation; mortality; longevity 


\section{Abstract \\ Background and Aims}

Plant phenology is a sensitive indicator of plant response to climate change. Observations of phenological events belowground for most ecosystems are difficult to obtain and are less characterized than those aboveground. Very little is known about the relationship between shoot and root phenology, especially in the field. We examined the influence of environmental factors and root morphological traits on fine root production and mortality in relation with shoot phenology in hybrid walnut trees (Juglans sp. L.) growing in three different climates (oceanic, continental and Mediterranean) along a latitudinal gradient in France.

\section{Methods}

Eight rhizotrons were installed at each site for 21 months to monitor tree root dynamics. Root elongation rate (RER), root initiation quantity (RIQ) and root mortality quantity (RMQ) were recorded frequently using a scanner and time-lapse camera. Leaf phenology, phenological phases and stem radial growth were also measured. Fine roots were classified into orders and 0-1 mm, 1-2 mm and 2-5 mm diameter classes and fine root longevity and risk of mortality was calculated per class of diameter at each site during different periods over the year.

\section{Results}

Root growth was not synchronous with leaf phenology in any climate or either year, but was synchronous with stem growth during the late growing season. A distinct bimodal pattern of root growth was observed during the aerial growing season but growth was negligible during the rest of the year. Maximal mean root elongation rates (RER) ranged from 2-5 mm during the late growing season (when leaves were still functioning), depending on climate. Mean RER was driven by soil temperature measured in the month preceding root growth in the oceanic climate site only. However, mean RER was significantly correlated with mean soil water 
potential measured in the month preceding growth at both Mediterranean (positive relationship) and oceanic (negative relationship) sites. Root diameter had no effect on RER. Mean RIQ was significantly higher at both continental and Mediterranean sites compared to the oceanic site. Soil temperature was a driver of mean RIQ during the late growing season at continental and Mediterranean sites only. Mean RMQ increased significantly with decreasing soil water potential during the late aerial growing season at the continental site only. Mean root longevity at the continental site was significantly greater than for roots at the oceanic and Mediterranean sites. Roots in the 0-1 mm and 1-2 mm diameter classes lived for significantly shorter periods compared to those in the 2-5 mm diameter class. First order roots lived longer than lateral roots at the Mediterranean site only and first order roots in the $0-1 \mathrm{~mm}$ diameter class had $44.5 \%$ less risk of mortality than that of lateral roots for the same class of diameter.

\section{Conclusions}

We conclude that factors driving root RER were not the same between climates. However, soil temperature was the best predictor of root initiation at all three sites, but drivers of root mortality remained largely undetermined.

\section{Abbreviations}

RER: Root elongation rate, RMQ: Root mortality quantity, RIQ: root initiation quantity, EGS: early growing season, LGS: late growing season, DS: dormant season, $\psi$ : Soil water potential. 


\section{Introduction}

Climate models predict that an increase in atmospheric $\mathrm{CO}_{2}$ concentration, precipitation and temperature could affect many biological phenomena and increase the frequency and magnitude of extreme weather events (Solomon et al 2007). Changes in plant phenology are considered to be a very sensitive and observable indicator of plant responses to climate change (Steinaker et al 2010, Morin et al 2010). The timing of above and below ground phenological events is important to assess ecosystem function and plant productivity (Fridley 2012, Richardson et al 2006). Aboveground phenological events include bud burst, leaf expansion and leaf fall, all of which have attracted attention because of the role they play in determining species' responses to climate change (Diez et al 2012). However, observations of phenological events belowground, including timing of root initiation, peak growth, survivorship and cessation of growth, are more difficult to obtain for most ecosystems and hence are less characterized especially in natural conditions.

Fine root dynamics, defined as elongation rate (Germon et al 2016, Jourdan et al 2008), production and mortality (Hendrick \& Pregitzer 1993b, Mao et al 2013b, McCormack et al 2014), turnover (Anderson et al 2003), survivorship (Anderson et al 2003, Kern et al 2004) and senescence (Huck et al 1987), play an essential role in ecosystem nutrient cycling and the global carbon budget (C) cycle (Vogt et al 1995, 1998, Gill \& Jackson 2000) because they regulate the storage of large quantities of C. It is widely acknowledged that fine root phenology could be strongly influenced by different factors (biotic and abiotic) throughout the year, and these factors alter patterns of root growth and longevity. Several studies found strong effects of abiotic factors on root elongation, such as soil temperature (Kuhns et al 1985, Wan et al 2002, Tanner et al 2006, Steinaker \& Wilson 2008, Steinaker et al 2010, Coll et al 2012), soil water content (Green et al 2005, Metcalfe et al 2008, Misson et al 2006, Block et al 2006) or air temperatures (M'bou et al 2008, Tierney \& Fahey 2002; Fukuzawa et al 2013). For example, 
Mao et al, (2013) studying Picea abies L. and Abies alba Mill. in montane and subalpine forest ecosystems have found that root elongation (RER) was significantly correlated with soil temperature above temperatures of $>1{ }^{\circ} \mathrm{C}$. Germon et al, (2016), studying walnut (Juglans regia $\times$ nigra L.) trees in a Mediterranean climate also found that RER was positively and significantly correlated with mean soil temperature. In contrast, other studies have found no correlations with abiotic factors (Hendrick \& Pregitzer 1993a, Hendrick \& Pregitzer 1993b, Hendrick and Pregitzer 1996a, Joslin \& Wolfe 1998, Joslin et al 2000) and suggest that endogenous factors, such as growth regulators (McAdam et al 2016), photoassimilate transport and photosynthates availability (Sloan et al 2016, Tierney \& Fahey 2002, Joslin et al 2000) are the main drivers of growth. Abramoff and Finzi, (2015) also suggested that endogenous cuing and allocation of stored carbohydrates were dominant drivers of root growth in Mediterranean trees. Radville et al, (2016), studying Arctic shrub-graminoid communities, showed that root growth occurred in near freezing temperatures and was not driven by soil temperature.

Although air temperature may be the most important environmental factor controlling the timing of aboveground growth, as reported by a number of studies (Menzel 2003, Radville et al 2016a, Wielgolaski 1999), the drivers of belowground phenology are less clear. We also have a poor understanding of the relationship between root growth and leaf phenology (Pregitzer et al 2000, McCormack et al 2014, Abramoff \& Finzi 2015) and how this relationship is affected by abiotic factors. More effort is needed in understanding such relationships. It is commonly assumed that root and shoot growth are asynchronous (Steinaker et al 2010, Abramoff \& Finzi 2015, Sloan et al 2016) with a peak of root growth in the early and late spring (Contador et al 2015, Germon et al 2016) or in the summer (Psarras et al 2000). However, several studies have shown that root growth can occur in a single flush but often occurs in multiple flushes throughout the growing season (Reich et al 1980, Harris et al 1995, Steinaker et al 2010) depending on resource availability either during a single seasonal pulse or multiple periods of 
favorable environmental conditions (McCormack et al 2014). In temperate forests, leaf growth occurs several weeks before root growth (Steinaker \& Wilson 2008, Abramoff \& Finzi 2015, Harris et al 1995). While Radville et al, (2016) in an arctic climate, and Abramoff and Finzi, (2015) reviewing data from a subtropical climate, showed that root growth precedes shoot growth by several weeks to several months (Radville et al 2016b, Broschat 1998).

Fine root turnover provides considerable amounts of $\mathrm{C}$ and nitrogen $(\mathrm{N})$ to the soil $(\mathrm{McCormack}$ et al 2012, Cox et al 1977, Hendrick \& Pregitzer 1993b, Wells \& Eissenstat 2001), often exceeding the amounts returned by leaf litter fall in some ecosystems (Vogt et al 1986). Fine root lifespan is considered an important root trait (Wang et al 2016), because it determines the quantity of root organic matter transferred to soil (Guo et al 2008) as well as exerting an indirect control on nutrient and water uptake efficiency (McCormack et al 2012). Root turnover varies widely within and among species and across ecosystems (Majdi et al 2005) but a fundamental understanding of the mechanisms that control fine root life span among different climates is poorly understood. Most published studies have related root lifespan either to endogenous factors such as root diameter and branch order (Guo et al 2008, Wang et al 2016), seasons of initiation, nitrogen $(\mathrm{N})$ concentration (McCormack et al 2012), root depth (Baddeley and Watson 2005) or to climatic factors such as temperature, water and nutrient availability (Chen \& Brassard 2013; Green et al 2005). However, knowledge of the influence of environmental factors on fine root life span remains limited. Understanding how endogenous and environmental factors co-vary to influence root longevity is therefore important in order to provide a better understanding of the contribution of fine roots to resource fluxes (Baddeley and Watson 2005).

In this study, we examined root elongation, initiation, mortality and survivorship of walnut trees (Juglans L.) growing in agroforest systems over 21 months along a climatic gradient in France. 
We focused on relating root phenology to leaf and stem phenology. We aimed at determining which factor most drives root growth over different phenological periods. We also characterized the relationship between root and shoot phenology, particularly in response to both temperature and precipitations. Rhizotrons were used to monitor monthly root growth and mortality in each site. We hypothesized that (i) shoot and root phenology are asynchronous regardless of the climate, (ii) the drivers of root growth and mortality are not the same between climates, (iii) root diameter is linked to elongation rate and is altered over phenological periods and between climates, and (iv) root longevity is altered among climates.

\section{Materials and methods}

\subsection{Study sites}

Root and shoot phenology of hybrid walnut (Juglans nigra $\times$ regia L.) were studied in three agroforestry systems along a latitudinal gradient in France. Trees were intercropped with pasture or crops (Fig. S1). The most northern site was located at Cormont, Pas de Calais, France $\left(50^{\circ} 333^{\prime} 27.87^{\prime \prime N}, 1^{\circ} 44^{\prime} 3.08^{\prime \prime E}\right.$, elevation $40 \mathrm{~m}$ a.s.l.). Climate was oceanic with a mean annual temperature of $11^{\circ} \mathrm{C}$ and a mean annual rainfall of $777.9 \mathrm{~mm}$ (Météo France, see section 3.2.2), thus the site is hereafter termed 'oceanic' (Fig S2). The agroforest comprised hybrid walnut (Juglans nigra $\times$ regia L.), common walnut (Juglans regia L., 1753), ash (Fraxinus L.), sycamore (Acer pseudoplatanus L.) and oak (Quercus L.), at $13 \mathrm{~m}$ x $7.5 \mathrm{~m}$ tree spacing, intercropped with permanent pasture (ovine pasture). All trees were planted in 1999 at a total current density of 100 trees ha $^{-1}$. The soil is silt loam (Table 1; Fig. S3) and at least $2.5 \mathrm{~m}$ deep, with the presence of the water table at this depth in June. The site is situated next to La Dordonne River. The mean diameter at breast height $(\mathrm{DBH})$ of walnut trees at the site was 0.30 $\pm 0.03 \mathrm{~m}$ and mean height was $14.75 \pm 3.50 \mathrm{~m}$. 
The second agroforest was located at Le Beil, Madic, Cantal, France (45²2'7.95"N, $2^{\circ} 28^{\prime} 1.46 " E$, elevation $530 \mathrm{~m}$ a.s.1.). Climate was continental with a mean annual temperature of $9.95^{\circ} \mathrm{C}$ and a mean annual rainfall of $1174 \mathrm{~mm}$ (Météo France, thus this site is hereafter termed 'continental' Figs. S1, S2). The agroforest comprised three transplanted tree species: hybrid walnut (J. major MJ209 x J. regia L.), cherry (Prunus avium) and sycamore (Acer pseudoplatanus), at $12 \mathrm{~m} \times 8 \mathrm{~m}$ tree spacing, intercropped with permanent pasture (ovine or bovine pasture). All trees were planted in 1994 at a density of 100 trees ha ${ }^{-1}$. The soil is sandy, particularly acidic, and attained an average maximum depth of $110 \mathrm{~cm}$ on a $5^{\circ}$ to $10^{\circ}$ (Table 1 , Fig. S3). The site is situated $300 \mathrm{~m}$ from Madic Lake. Mean DBH of all walnut cultivars at the site was $0.20 \pm 0.02 \mathrm{~m}$ and mean height was $12.09 \pm 1.30 \mathrm{~m}$.

The third agroforest was located at the Restinclières experimental site, $15 \mathrm{~km}$ north of Montpellier, Department Hérault, France ( $43^{\circ} 43^{\prime} \mathrm{N}, 4^{\circ} 01^{\prime} \mathrm{E}$, elevation $54 \mathrm{~m}$ a.s.1.). The climate is sub-humid Mediterranean with a mean annual temperature of $15.4{ }^{\circ} \mathrm{C}$ and a mean annual rainfall of $873 \mathrm{~mm}$ (this site is henceforth termed 'Mediterranean,' Figs. S1, S2). The study plot comprised hybrid walnut trees (Juglans regia $\times$ nigra L. cv. NG23), at $13 \times 4 \mathrm{~m}$ tree spacing, intercropped with durum wheat (Triticum turgidum L. subsp. durum (Desf.) Husn). However, rapeseed (Brassica napus L.) was also cultivated in 1998, 2001 and 2006, and pea (Pisum sativum L.) in 2010 and 2016. All walnut trees were planted in 1995 in lines oriented east west, and the current density is 110 trees $\mathrm{ha}^{-1}$. The annual crop was fertilized with approximately 150 $\mathrm{kg} \mathrm{N} \mathrm{ha}^{-1} \mathrm{yr}^{-1}$ (Cardinael et al 2015). The soil is a silty clay deep alluvial soil (25\% clay and $60 \%$ silt) with a depth $>4 \mathrm{~m}$, and slope angle is $<1^{\circ}$ within the site (Mulia and Dupraz 2006). The site is near the Lez river watershed and the depth from the soil surface to the water table usually oscillates between $5 \mathrm{~m}$ in winter and $7 \mathrm{~m}$ in the summer (Cardinael et al 2015). More details about the experimental site are available in (Dupraz et al 1999, Mulia and Dupraz 2006, 
Cardinael et al 2015). Mean DBH of all walnut trees at the site was $0.24 \pm 0.13 \mathrm{~m}$ and mean height was $11.09 \pm 2.50 \mathrm{~m}$.

\subsection{Climatic data}

Global precipitation data for the three sites were obtained from Météo-France. Weather stations were located at Le Touquet, (oceanic: $50^{\circ} 30^{\prime} 48^{\prime \prime} \mathrm{N}, 1^{\circ} 37^{\prime} 18^{\prime \prime} \mathrm{E}$, elevation $5 \mathrm{~m}$ a.s.1.), Station Naves (continental:, 45 $19^{\prime} 12^{\prime \prime} \mathrm{N}, 1^{\circ} 46^{\prime} 18^{\prime \prime E}$, elevation $450 \mathrm{~m}$ a.s.1.) and Restinclières (Mediterranean: $43.702 \mathrm{~N}$ et 3,86 E, elevation $100 \mathrm{~m}$ a.s.1.). Air temperatures were measured in the shade at a height of $1.5 \mathrm{~m}$ at each site and soil temperatures were measured in two soil layers (10 and $60 \mathrm{~cm}$ ) per site, using Thermochron iButtons (DS1921G) (Hubbart et al 2005). All sensors were programmed to measure the temperature twice a day ( 2 a.m and 2 p.m). Soil water potential (noted $\psi$ hereafter) was measured using Irrometers (WaterMark, IRROMETER Company, Inc. USA) installed at each site at depths of 10 and $60 \mathrm{~cm}$.

\subsection{Rhizotron installation}

To measure tree root elongation and mortality along the climatic gradient, we installed rhizotrons, also called root windows, in pits at each field site (Fig. S4). Rhizotrons comprised transparent polyvinylchloride (PVC) sheets placed against the soil profile, through which root growth dynamics can be observed (Reich, et al., 1980; Misra, 1999; Mao et al., 2014). In the oceanic site, four trenches ( $2 \mathrm{~m}$ long x $1 \mathrm{~m}$ wide $\mathrm{x} 2 \mathrm{~m}$ deep) were dug in one row of trees and each pit was located at $2 \mathrm{~m}$ from the tree trunk. One rhizotron was installed on each opposing face of the trench ( $\mathrm{n}=8$ rhizotrons).

In the continental agroforest (Madic), we dug eight ( $1 \mathrm{~m}$ long $\mathrm{x} 1 \mathrm{~m}$ wide $\mathrm{x} 1 \mathrm{~m}$ depth) trenches in three rows of trees. Each trench was at a distance of $2 \mathrm{~m}$ from the nearest tree trunk. Eight rhizotrons $(50 \mathrm{~cm}$ long x $50 \mathrm{~cm}$ wide x $0.5 \mathrm{~cm}$ thick), were installed. 
At the Mediterranean site, one pit (5 m length x $1.5 \mathrm{~m}$ width $\mathrm{x} 4 \mathrm{~m}$ depth) was dug in March 2012 between two walnut trees on the same tree row (Fig. S5) (Cardinael et al. 2015). The pit was reinforced with wooden beams to avoid collapse of the pit walls. In June 2014, two rhizotrons (100 cm long x $80 \mathrm{~cm}$ wide x $0.5 \mathrm{~cm}$ thick) were installed as well as eight smaller windows (65 cm long x $30 \mathrm{~cm}$ wide x $0.5 \mathrm{~cm}$ thick) at depths of 20, 115, 220 and $320 \mathrm{~cm}$.

Where the rhizotrons were to be placed on the soil wall, we gently removed the soil to make a flat surface and cut all roots on the profile with secateurs. The soil removed during the digging of the trenches was kept aside, and then sieved through a $5 \mathrm{~mm}$ sieve and air-dried for several hours. The sieved and air-dried soil was then poured into the space between the window and the soil profile and slowly compacted using a wooden plank. Rhizotrons were placed vertically against the soil profile at an angle of $15^{\circ}$. This angle will permit the roots to grow downwards due to positive geotropism (Huck \& Taylor 1982; Mao et al 2013). Each rhizotron was covered with foil backed felt insulation and black plastic sheeting to protect roots from light and temperature variations. All pits were then covered with wooden boards and corrugated plastic or a metallic roof to avoid damage from passing animals and to prevent direct rainfall and sunlight on the rhizotrons. In the first three months after installation, no root growth was recorded because soil disturbance during rhizotron installation causes over estimations of root growth (Strand et al 2008, Mohamed et al. 2017).

\subsection{Measurements of root growth}

To measure fine root growth dynamics, we either scanned rhizotrons or used a time-lapse camera to automatically take pictures before then analyzing images (Mohamed et al 2017). In the continental and Mediterranean sites, a scan of each rhizotron (between two and four images per window depending on the size of the window) was taken at monthly intervals over 21 months using an Epson Perfection V370 flatbed scanner with a high optical resolution of 4800 dpi (Fig. S6). 
At the oceanic site, a time-lapse camera (Cuddeback Attack, U.S.A.) was placed on a wooden cleat in front of each rhizotron at a distance of $90 \mathrm{~cm}$ from the rhizotron (Fig. S6). Photographs were taken daily at 2 a.m. and 2 p.m. for 21 months. The time-lapse cameras ran automatically for several months at a time using alkaline batteries. In September 2014, the trench at the Mediterranean site was flooded due to exceptionally strong rainfall, therefore all rhizotrons were reinstalled in March 2015. No data were recorded from September 2014 to March 2015, and data were recorded from March to June 2015 but not used in the statistical analysis. Similarly, at the oceanic site, nearly all trenches were flooded due to strong rainfall in January 2015 and the proximity of the water table, and almost half the cameras were damaged. In March 2015, all cameras were replaced and no data were recorded from January 2015 to March 2015. To avoid the same problem the following year, we removed cameras from November 2015 to March 2016, therefore data are missing for this period also.

Monthly measurements of root emergence, mortality and elongation were carried out immediately after roots were observed in each rhizotron (and after the first three months had passed) until October 2014. Roots were classified into three diameter classes: (0-1) mm, (1-2) $\mathrm{mm}$, and (2-5) $\mathrm{mm}$. However for measurements from the camera method, because of an overestimation of diameters (Mohamed et al., 2017), we corrected the value of root diameter by using the following equation:

$y=0.43 x$

Where y represents the value corrected of root diameter, $\mathrm{x}$ represents the real value of the diameter taken by the camera. 0.43 is the relative value corresponding to the mean gap between scanner measurement and camera measurement. We also classified root topology into two orders: 'parent' or 'child' (SmartRoot software). The effect of root topological orders at the oceanic site was excluded from the analysis because a negligible number of lateral roots emerged. 
In previous studies, root mortality was assumed to occur when the root became darker in color (West et al 2004) or when it disappeared (Baddeley \& Watson 2005). In some studies, both criteria were applied (Wells \& Eissenstat 2001, Anderson et al 2009). In our study, color was the only criterion applied (Mao et al 2013a), as root death can occur before its disappearance (Hooker et al., 2000). We declared the root dead when it was turning black with no growth between two or more successive sessions until the last observation date occurred.

\subsection{Image analysis}

Once images of root growth had been acquired, we conducted analysed images using the semiautomated SmartRoot software (Lobet et al 2011). SmartRoot is an operating system independent freeware based on ImageJ and using cross-platform standards (RSML, SQL, and Java) for communication with data analysis softwares (Lobet et al 2011, Mathieu et al 2015).

Before analyzing roots, when necessary, images need "stitching" together (e.g. with Adobe Photoshop CS3 software), if several have been taken for the same rhizotron (when the rhizotron surface area was greater than the field of the scanner). In the case of this study, we transformed all images to 8 bit gray scale and then inverted them using ImageJ software so that roots were darker than the background of the image. The length and diameter of each root produced during one interval time (i.e. one month) were calculated for each rhizotron (Mohamed et al. 2017). Before analyzing a new sequence of images, SmartRoot provides the user with an icon to import the traces of the same roots from the previous image data file to superimpose them on this new image, which helps the estimation of the evolution of root length. This preceding image also helps determine whether the root is live (walnut roots are usually cream in color) or dead (turning black) (Huck \& Taylor 1982, Mao et al 2013b).

\subsection{Aboveground phenology and radial growth}


We assessed the timing of shoot production through changes in the phenological phases of leaves throughout the year. We divided the year into three phenological periods, early growing season (from budburst to $100 \%$ leafing out of early green leaves), late growing season (100\% leafing out to leaf-fall) and dormancy (leaf-fall to budburst, Fig. 1). Shoot phenological periods were recorded using a time-lapse camera (Wingscapes TimelapseCam8.0) at a resolution of 5 megapixels in the oceanic and continental agroforests. One camera per site was placed on the trunk of one tree facing a line of trees. Photographs were taken daily at 12 a.m. and 12 p.m. At the Mediterranean site, shoot phenological periods were recorded visually using binoculars.

During the bud-burst period, visual measurements were made daily.

We also measured the radial growth of tree trunks by installing dendrometers (Increment Sensor DB20) on eight trees per site. The dendrometers are girth bands, comprising a steel band, spring and nonius scale. Bands were placed on the stem; at a height of $1.3 \mathrm{~m}$. Measured values are read at the nonius scale with $0.1 \mathrm{~mm}$ precision. Readings were made monthly at both continental and Mediterranean sites. However, readings were made only every three months at the oceanic site because of difficulties with site access. Tree height was recorded annually after leaf shedding using a hypsometer Vertex (Quebec, Canada).

\subsection{Root growth and mortality dynamics}

We used the following methods to estimate root elongation rate (RER), initiation and mortality:

(i) individual root growth was evaluated by calculating the difference between root length at $t_{-1}$ and at $\mathrm{t}$. To determine daily RER, the mean of all individual root lengths produced between time $\mathrm{t}$ and $\mathrm{t}_{-1}$ was divided by the duration of the corresponding period:

$$
R E R_{t-1, t}=\frac{\operatorname{len} . t_{t}-l_{\text {en.t-l }}}{P t_{-l, t}}
$$



where, $R E R_{t-1, t}$ is the daily root elongation rate (in $\mathrm{mm} /$ day) from inventory time $\mathrm{t}-1$ to $\mathrm{t}$; len ${ }_{t-1}$ and $l e n_{t}$ are the lengths of the root $\mathrm{n}$ at inventory time $t-1$ and $\mathrm{t}$, respectively; $p_{t-1, t}$ is the period in days between inventory time $t_{-1}$ and $t$.

(ii) Monthly mean root initiation quantity (RIQ), was calculated as the mean number of new roots initiated between time $t$ and $t_{-1}$.

(iii) Monthly mean root mortality quantity (RMQ) was calculated as the mean number of dead roots between $t$ and $t-1$ only when alive roots were present.

\subsection{Statistical analysis}

All indicators of root dynamics, including mean RER (for growing roots only), mean RIQ and mean RMQ (when the total number of alive roots was $>0$ ) were calculated using $\mathrm{R}$ software Version 2.15.3 (R Development Core Team 2013). A Shapiro-Wilk test was performed before each test to test if data followed a normal distribution and homogeneity of variances was checked. For data not normally distributed, analyses were performed by a Kruskal-Wallis test. Effects of season, site, diameter classes and topological orders were tested on each variable. A post-hoc analysis was performed when the Kruskal-Wallis result was significant, using a Nemenyi test of Kruskal Wallis at $\mathrm{p}<0.05$ to determine which levels of the independent variable differed from each other level. Spearman's rank correlations (Spearman) were performed to determine the relationship between the climatic variables (mean soil and air temperatures and mean $\psi$ ) of the both the current and preceding months, and the mean RER, mean RIQ and mean RMQ.

A Cox Proportional Hazard Model was used to analyze the effects of different varying factors on root mortality and to calculate root longevity and risk of mortality. Factors used as variables included sites, phenological period, diameter classes and topology orders. Different Cox Hazard Models were performed for two topological orders: parent and child order (SmartRoot 
software). We performed the statistical test only when the sample size was $>20$ for each category (topology order, diameter classes, sites, time periods). All analyses were performed using R software, Version 2.15.3 (R Development Core Team 2013) at a significance level of $<0.05$.

\section{Results}

\subsection{Latitudinal gradient of meteorological and soil hydrological data}

Mean annual temperature over the two year period was $11.7^{\circ} \mathrm{C}$ (oceanic), $12.4^{\circ} \mathrm{C}$ (continental) and $14.8^{\circ} \mathrm{C}$ (Mediterranean). Mean monthly air temperature over the same period was lowest in December at all field sites (ranging from $3.1^{\circ} \mathrm{C}$ to $7.6^{\circ} \mathrm{C}$; Fig. 1), and highest in July at the oceanic $\left(17.8^{\circ} \mathrm{C}\right)$, continental $\left(20.6^{\circ} \mathrm{C}\right)$ and Mediterranean sites $\left(24.3^{\circ} \mathrm{C}\right)$ (Fig. 2). Mean soil temperatures during the early growing season at the oceanic site was $12.7^{\circ} \mathrm{C}$, compared to $14.1^{\circ} \mathrm{C}$ and $11.9^{\circ} \mathrm{C}$ at the continental and Mediterranean sites, respectively. Mean soil temperatures were $13.9^{\circ} \mathrm{C}$ (oceanic), $15.8^{\circ} \mathrm{C}$ (continental) and $17.9^{\circ} \mathrm{C}$ (Mediterranean) during the late growing season and $9.6^{\circ} \mathrm{C}$ (oceanic), $10.8^{\circ} \mathrm{C}$ (continental), $6.7^{\circ} \mathrm{C}$ (Mediterranean) during the dormant season.

Average annual precipitation over 2014 and 2015 was $910 \mathrm{~mm}$ (oceanic), $1056 \mathrm{~mm}$ (continental) and $938 \mathrm{~mm}$ (Mediterranean) (Fig. 2). Rainfall at the Mediterranean site was highly variable between the two years, with $1264 \mathrm{~mm}$ in 2014 and only $613 \mathrm{~mm}$ in 2015 (Fig. 2). A negative and significant $(\mathrm{p}<0.001, \mathrm{r}=-0.40)$ correlation was found between total annual rainfall and $\psi$.

Mean annual soil water potential was significantly higher at the Mediterranean site than those of continental and oceanic sites $(\mathrm{p}<000.1)$ and the oceanic site had a significantly higher $\psi$ than the continental site $(\mathrm{p}<0.001)$. 
Mean annual soil and air temperatures at the Mediterranean site were both significantly higher than those at the continental and oceanic sites $(\mathrm{p}<0.001)$ and the oceanic site had a significantly greater mean soil temperature compared to the continental site $(\mathrm{p}=0.04)$. However, no significant differences were found in mean air temperature between oceanic and continental sites $(\mathrm{p}=0.17)$.

\subsection{Leaf phenology}

The date of budburst differed among sites: the Mediterranean trees in 2015 had an earlier budburst (18 April 2015) than the continental and oceanic climates by 15 days and 27 days, respectively. In 2016, this difference increased to 21 and 28 days, respectively (Table 2). The Mediterranean trees had an earlier leaf unfolding date (2 June 2015) than the continental and oceanic climates by 3 and 16 days, respectively. Mediterranean trees had later leaf fall (18 November 2014 and 12 November 2015) than the continental (6 days in 2014 and 15 days in 2015) and oceanic sites (10 days in 2014 and 9 days in 2015).

\subsection{Stem phenology}

The timing of root growth was synchronous with that of stem growth during the late growing season (from June to November) in both study sites (Fig. 3). Stem radial growth started when trees had $100 \%$ of leaf unfolding (the onset of late growing season). Root and stem growth had an antagonistic growth pattern (Fig. 3), i.e. peaks of root growth occurred inversely to those of stem growth. Stem growth then dropped sharply with leaf fall. The length of the radial growing season was shorter than that of roots by 86 days and 73 days at both continental and Mediterranean sites, respectively.

\subsection{Root elongation rate (RER)}

Mean RER for growing roots at all sites was influenced significantly by season, with a bimodal distinct flush of root growth observed during the aerial growing season (Fig. 4), and negligible 
growth during the rest of the year. Peaks of mean RER always lagged behind those for budburst. In 2015, mean RER was initiated before budburst in both oceanic (28 days) and continental (26 days) climates. However at the Mediterranean site, budburst preceded root elongation by 28 days in 2015. Mean RER peaked in June (Mediterranean) or July (oceanic and continental; Fig. 2), before decreasing and then peaking to a lesser extent in August for the Mediterranean site, and September for the oceanic and continental sites (Fig. 4). When mean RER (during all observation periods) and between all sites was compared, mean RER was significantly higher $(p=0.01)$ at the oceanic site compared to the continental site only.

No significant relationships were found between RER and root diameter classes. No significant differences were found in RER of any roots between the early and dormant seasons.

When all root data were combined, mean RER was positively and significantly correlated with the mean air and soil temperatures of the month preceding the RER measurement at the oceanic $\left(\mathrm{P}<0001, \mathrm{r}_{\mathrm{s}}=0.55\right)$ and continental $\left(\mathrm{P}<0001, \mathrm{r}_{\mathrm{s}}=0.48\right)$ sites only (Fig. 5a,b). Mean RER was correlated with mean $\psi$ at the oceanic site only (Fig. 5c, $\mathrm{P}<0.001, \mathrm{r}_{\mathrm{s}}=0.55$ ). However, when mean RER of roots growing during the aerial growing season was examined, positive and significant correlations were found between mean RER and soil temperature (Fig. 6a, p=0.002, $\mathrm{r}_{\mathrm{s}}=0.61$ ) and mean RER and air temperature (Fig. $6 \mathrm{~b}, \mathrm{p}=0.004, \mathrm{r}_{\mathrm{s}}=0.48$ ) of the month preceding growth at the oceanic site only. The mean RER was significantly correlated with mean $\psi$ in both oceanic (negatively) (Fig. 6c, p=0.004, $\mathrm{r}_{\mathrm{s}}=-0.48$ ) and Mediterranean (positively) (Fig. 6c, $\left.\mathrm{p}=0.05, \mathrm{r}_{\mathrm{s}}=0.50\right)$ sites only.

\subsection{Comparing and above and belowground phenology}

Phenological periods of growth differed between sites. In 2015, the Mediterranean climate had a longer aerial growing season (208 days) than continental and oceanic climates by 30 days and 36 days, respectively. In 2014, the dormant season was shorter at the Mediterranean site (151 
401

402

403

404

405

406

407

408

409

410

411

412

413

414

415

416

417

418

419

420

421

422

423

424

days) compared to continental (172 days) and oceanic sites (188 days). However, in 2015, the length of the growing season was similar in oceanic and Mediterranean climates but the dormant season was longer by 36 days at the continental site (Table 2). The duration of the growing season of roots was longer than that for leaves for the oceanic (38 days), continental (62 days) and Mediterranean (8 days) sites (Table 2). Root growth was not synchronous with leaf phenology in any climate or either year. However, root elongation was synchronous with trunk growth in the three climates (Fig 4).

\subsection{Mean monthly root initiation and mortality quantities}

Mean RIQ was always highest during the late growing season compared to the other seasons. The first peak of root appearance at each site was 3 months after rhizotron installation (October 2014 at both the oceanic and continental sites and in June 2015 at the Mediterranean site). In 2015, peaks of mean RIQ were found in June at the oceanic site $(1.17 \pm 2.32$ roots $)$, in July at the continental site $(3.6 \pm 6.02$ roots $)$ and in October at Mediterranean site $(1.71 \pm 3.29$ roots; Fig. 7). Each peak of mRIQ was followed immediately by a peak of mRMQ in all climates during the late growing season (Fig. 7). A significantly lower number of roots was initiated $(\mathrm{p}=0.02)$ at the oceanic site $(0.66 \pm 1.87$ roots $)$ compared to both continental $(0.7 \pm 5.3$ roots $)$ and Mediterranean climates $(1.9 \pm 4.9$ roots). No significant differences in mean RIQ were found between continental and Mediterranean sites.

No significant differences in mean RMQ were found between climates between early and late growing seasons. Mean RMQ was significantly higher in the late growing season compared to the dormant season $(\mathrm{p}=0.009)$.

During the late growing season, mean RIQ was not correlated with mean $\psi$ in any of the three climates (Fig. 8). Significant negative correlations were found between mean RIQ and mean soil temperature of the preceding month at the continental $\left(\mathrm{P}<0.001, \mathrm{r}_{\mathrm{s}}=-0.28\right)$ and 
Mediterranean $\left(\mathrm{P}<0.001, \mathrm{r}_{\mathrm{s}}=-0.54\right)$ sites only (Fig. 8). Mean air temperature of the preceding month was negatively correlated $\left(\mathrm{p}=0.002, \mathrm{r}_{\mathrm{s}}=-0.37\right)$ with mean RIQ in the Mediterranean climate only (Fig. 8). However, mean RMQ increased rapidly with the increase of mean soil temperature and mean $\psi$ and peaked when $\psi$ was maximal at the continental site only (Fig. 9). However, mean RMQ was not correlated with mean soil or air temperatures or mean $\psi$ in either oceanic or Mediterranean sites (Fig. 9). When all factors were considered together, mean RIQ and mean RMQ of first order roots (parent) was significantly greater than lateral order (child) roots at the continental site only $(\mathrm{p}<0.001)$.

\subsection{Root longevity and risk of mortality}

Cox's proportional hazards regressions showed that when all root diameter classes were grouped together, mean root longevity at the continental site was significantly greater than for roots at the oceanic $(\mathrm{z}=7.7, \mathrm{p}<0.001)$ and Mediterranean $(\mathrm{z}=14.2, \mathrm{p}<0.001)$ sites. The longevity of roots at the Mediterranean site was significantly shorter than at the oceanic site (Fig. 10a, Table 3). Compared to the continental climate, the risk of mortality was 2.7 times greater for roots from the Mediterranean site and 2.1 times greater for roots from the oceanic site. The phenological period had an important effect on root longevity at continental site but not at oceanic and Mediterranean sites during the observation period. At the continental site, compared to the dormant season, the risk of mortality was 1.8 times more during the early growing season and 1.7 times more during the late growing season (Fig. 10b). No significant differences in longevity were found between growing seasons at the other two sites. Root diameter classes had the largest effect on root longevity compared with other factors. When lateral roots were excluded from the analysis (for all growth periods combined), roots in the 0.1 $\mathrm{mm}$ diameter class lived for significantly shorter periods compared to those in the $2-5 \mathrm{~mm}$ diameter class at continental $(\mathrm{z}=-1.65, \mathrm{p}=0.006)$ and Mediterranean $(\mathrm{z}=-3.36, \mathrm{p}=0.0007)$ sites 
only. However, no significant differences in longevity were found between roots from the $0-1$ $\mathrm{mm}$ and 1-2 $\mathrm{mm}$ diameter classes (Fig. 10c). At the continental site, roots in the $2-5 \mathrm{~mm}$ diameter class had $38 \%$ less risk of mortality than roots in the $0-1 \mathrm{~mm}$ diameter class. At the Mediterranean site, roots in the 2-5 mm diameter class had $61 \%$ less risk of mortality than those from 0-1 diameter class. When all factors were considered together, except for topological order, first order roots lived longer than lateral roots at the Mediterranean site $(z=-3, p=0.005)$ but not at the continental site. At the Mediterranean site, first order roots in the 0-1 mm diameter class had $44.5 \%$ less risk of mortality $(\mathrm{z}=-3.04, \mathrm{p}=0.002)$ than that of lateral roots for the same class of diameter, but no differences in longevity were found at the continental site. First order roots in the 1-2 mm diameter class had significantly longer longevity $(\mathrm{z}=-2.7, \mathrm{p}=0.005)$ than lateral roots of the same class of diameter at the Mediterranean climate, but not at the continental site.

\section{Discussion}

We did not find any significant differences between climates with regard to the phenology of root dynamics throughout the year. Walnut hybrids had a distinct bimodal pattern of root growth during the aerial growing season in all three climates, with much less root growth during the aerial dormant season.

\section{Temperature and soil water potential effects on root growth dynamics}

Mean RER of walnut trees was positively correlated with both mean soil and air temperatures at the oceanic and continental sites only. It is surprising that we did not find any relationships between mean RER and temperature at the Mediterranean site, as Germon et al (2016) found a highly significant and positive correlation between RER and soil temperature for the same stand of walnut cultivars. However, mean RER was significantly and positively correlated with mean air and soil temperatures during the late growing season, where the highest peaks of root growth 
were found at the oceanic site only. Mean RER at the oceanic site was also significantly and negatively correlated with mean soil $\psi$ of the preceding month, i.e. as was also found by Joslin et al., (2001) for oak (Quercus prinus L.) and white oak (Quercus alba L.) growing in a subtropical climate. However, mean RER at the Mediterranean site was significantly but positively correlated with mean soil $\psi$, similar to results for Abies balsamea L. (Olesinski et al 2011) and Quercus alba L. seedlings (Reich et al 1980). At the continental site, the absence of correlations of RER with any climatic factors is in conflict with other studies which indicate that air and soil temperatures are the prominent factors driving RER (Misra 1999, Hendricks et al 2006, Mao et al 2013b, McCormack and Guo 2014, Germon et al 2016, Gill \& Jackson 2000), especially during the growing season in temperate climates. In our study, for all climates, soil temperature never reached below $3^{\circ} \mathrm{C}$ or above $21^{\circ} \mathrm{C}$ during the entire study period. Most root elongation occurred when the soil temperature was within the range $9-17^{\circ} \mathrm{C}$. Our results are contradictory to those found by Heninger and White (1974) and Lyr (1996) who showed that the highest rates of root growth of deciduous trees under non limiting moisture conditions were usually found when soil temperatures were above $20^{\circ} \mathrm{C}$. Here we found that the highest rate of elongation occurred when temperatures were between $14-17^{\circ} \mathrm{C}$. At the oceanic site, soil temperature varied little throughout the year, with few extreme values, whereas the continental site had large seasonal differences in soil temperature. Mean soil $\psi$ at the Mediterranean site was significantly lower than at the oceanic and continental sites. Soil $\psi$ can limit root elongation by either excessive water resulting in anaerobic conditions or inadequate water to support growth (Joslin et al 2001). Previous studies have shown that walnut seedlings have a low resistance to water stress and are sensitive to waterlogging both between and within cultivars (Mapelli et al 1995), a phenomenon that we demonstrated (waterlogging occurred in the oceanic site and water stress in occurred in the Mediterranean site). 
Our results demonstrated a decline in RER with the decrease of mean soil $\psi$ at the

499 Mediterranean site, suggesting that soil water is limiting for root growth in the superficial layers, as found for other broadleaf species (e.g. Wan et al., 2002 studying Gutierrezia

501

502

503

504

505

506

507

508

509

510

511

512

513

514

515

516

517

518

519

520

521 sarothrae). However, at the oceanic site, our results showed that RER augmented with the decrease of mean soil $\psi$ and declined with the increase of mean air and soil temperatures, also found by Joslin et al, (2001) in Quercus prinus L.. Our results indicate that at the oceanic site, soil temperature played a major role in driving root elongation, as also found by (Germon et al 2016, Mao et al 2013b, McCormack and Guo 2014) and that soil $\psi$ played an indirect role, but as both factors co-vary during the late growing season, it is difficult to disentangle their distinct effects on root growth.

Our results suggest that, once soil temperature is favorable for roots, and if there are no extreme occurrences of temperature throughout the year, then other limiting factors will drive root growth. For example, root growth decreased substantially irrespective of soil temperature during a period of drought (Reich et al, 1980) (similar to the climatic conditions at our Mediterranean site).

Surprisingly, and contrary to the observations of previous authors (e.g. Germon et al, (2016) working on walnut cultivars, Mao et al, (2013) studying $P$. abies and A. alba and Kern et al (2004) studying Populus deltoides Bartr), mean RER was not related to root diameter. While trees growing at the continental site produced many short-lived lateral roots, no lateral root initiation occurred at the Mediterranean and oceanic sites. Soil conditions could have played a role because strong soil acidity has been showed to increase heavy metal solubility and hinder the development of lateral roots (Kahle 1993). The lower phosphorus content at the continental site would also influence root architecture and lateral root development, as roots increase their exploration and scavenging of the soil (Rao et al. 2015). 
Mean RIQ and mean RMQ were related to annual variations in soil temperature, except for the first peak of root initiation which occurred three months after rhizotron installation at the three sites regardless of the phenological period (Johnson 2001, Baddeley \& Watson 2005) . We consider this result as an artefact of the rhizotron method, which led to an overestimation of the fine root production (Hendrick \& Pregitzer 1996a, Majdi 1996, Majdi et al 2005, Green et al 2005, Metcalfe et al 2008). The second peak of mean RIQ was found during the late growing season, regardless of climate, and was followed immediately by a peak in mean RMQ. Therefore, the major pulse of hybrid walnut root production is inherently programmed to occur during the late growing season (June-November) with significantly less production in the aerial dormant season, as also found in many deciduous tree species in temperate zones (e.g., Joslin 2000; Hendrick \& Pregitzer, 1996a,b, Joslin et al 2000). Psarras et al, (2000), also found a peak of root emergence in Malus sylvestris (L.) in late June and early July, which coincided partially with major phases of shoot and fruit growth.

In our study, mean RIQ was significantly higher at the continental site compared to the two other sites during the late growing season. A first possible reason is to link to the phenomenon responsible for the higher development of lateral roots. Another explanation for this greater productivity is that soil and air temperatures and $\psi$ were optimal for growth during the late growing season. Mean RIQ was correlated with mean soil temperature at the Mediterranean and continental sites only, as was expected (Comas et al, 2005, Mao et al 2013a), but the lack of significant relationships at the oceanic site is not understood. However, air temperature at the three sites were correlated with mean RIQ during the late growing season. These results are consistent with the observations of Radville et al (2016a), Fukuzawa et al (2013) and Steinaker et al (2010), who demonstrated that temperature was a main driver of root initiation in temperate environments. Tierney et al, (2003) also showed that mean fine root production of sugar maple trees was strongly associated with mean air temperature but not soil moisture or nutrient 
availability. However, in a literature review, Abramoff \& Finzi (2015) suggested that for

548 Mediterranean trees, endogenous factors and the allocation of stored carbohydrates were

549 dominant drivers of root growth.

550 We found that mean RMQ did not differ significantly between sites and was highest during the

551 late growing season. These results are contrary to those of Kern et al, (2004), working on

552 Populus deltoides Bartr. in a continental climate, who found that mortality was greatest after

553 the end of the growing season. Mean RMQ was correlated with both mean soil temperature and

554 mean $\psi$ at the continental climate only. Our results are in agreement with the finding of Harris

555

556

557

558

559

560

561

562

563

564

565

566

567

568

569

570

et al (1995), studying Acer saccharum in a moderate continental climate, who showed that root

mortality increased in warmer soil temperatures. We consider the peak of mortality as a consequence of a trade-off between competing plant sinks to balance carbohydrate availability.

These results suggest that, if other factors are equal, the growth of new roots and the death of existing roots are accelerated with the increase of soil temperature.

\section{Above and belowground phenological relationships}

The timing of root growth was asynchronous with that of budburst at all sites, and the spring root flush occurred several weeks after budburst. As both budburst and root emergence are very sensitive to local temperatures (Du and Fang 2014, Tierney and Fahey 2002), a rapid increase in air temperature in April/May would stimulate budburst quickly. Soil is buffered against rapid changes in air temperature, therefore the subsequent cambial activity in roots would take longer to occur, and root flushes will usually occur after bud burst (Pregitzer et al 2000). Maximal root and radial stem growth both took place during the late growing season. Peaks of stem and root radial growth at the Mediterranean site occurred later in the season (September) than at both other sites (July), possibly linked to precipitation events after the hot, dry summer. 
571 Our results suggest a trade-off between competing plant sinks (Radville et al 2016a). For 572 example, fine root growth was likely fueled by non-structural carbohydrates (NSC) stored 573 before the onset of the aerial growing season, as suggested by Gaudinski et al, (2009) and Najar

574 et al (2014). The decrease in fine root elongation observed in August (oceanic and continental 575 sites) and July (Mediterranean site) may be due to NSC being used for radial growth and fruit 576 production. NSC production from photosynthesis would then increase during the summer, 577 fueling a second root flush, before leaf senescence in November. The decrease in photosynthetic 578 rates at the end of the growing season would result in less NSC being available for radial 579 growth, which decreases rapidly in September - October (Radville et al 2016a, Du and Fang 580 2014, Abramoff \& Finzi 2015). Minor root elongation can occur during aerial dormancy at all 581 sites, using local NSC stocks as energy for growth.

\section{Root longevity and risk of mortality}

584

585

We showed that root longevity differed significantly between climates and roots lived longest at the continental site. Fine roots at this site were significantly thicker and root diameter was correlated to longevity, as also shown by e.g., Anderson et al, (2003) and Wells and Eissenstat, (2001). Roots in the 0-1 mm and 1-2 mm diameter classes lived for significantly shorter periods compared to those in the 2-5 mm diameter class at continental and Mediterranean sites only. Thicker roots have lower $\mathrm{N}$ concentration, lower surface area and higher $\mathrm{C}$ content than finer roots and thus longevity is increased because of a decrease in metabolic activity (McCormack et al 2012, Guo et al 2004, 2008, Baddeley \& Watson 2005).

As root traits may be prominent drivers of ecosystem processes (McCormack et al, 2015), and as root topological order can influence traits, considering root topology when studying root survivorship is considered fundamental (Guo et al, 2008). In our study, first order roots lived longer than lateral roots at the Mediterranean site only and first order roots in the both $0-1 \mathrm{~mm}$ 
and 1-2 mm diameter classes had $44.5 \%$ less risk of mortality than that of lateral roots for the same class of diameter, as also found by McCormack et al (2012). Guo et al, (2008) also showed in longleaf pine (Pinus palustris. Mill.) that higher order roots had $46 \%$ greater longevity than roots one order lower. We suppose that first order roots live longer than lateral roots because of the greater resource investment in their construction. Finer lateral roots cost less to construct, and so can grow quickly when needed for soil exploration and resource capture.

The risk of root mortality at the continental site was significantly greater during the growing season compared to the aerial dormant season, as also found in apple (Malus sylvestris. L) (Psarras et al 2000). However, our results are contrary to those of Wang et al, (2016), who found that the mortality hazard ratio of Picea abies and Abies alba initiated in the late growing season was reduced by $26.8 \%$ compared to roots that emerged in the early growing season. Root longevity usually decreases with increasing temperature (King et al 1999, Majdi et al 2005), therefore, as temperature fluctuations were more extreme at the continental site, roots may die more quickly as summer temperatures increase rapidly. As root density was higher during growing season at the continental site, soil herbivores and pathogens may be more active (Guo et al 2008).

In conclusion, although root studies have increased significantly in recent years, it is still difficult to draw any firm conclusions about how variations in climate will affect root dynamics and in turn how changes in dynamics might affect plant production or carbon cycling in soil. The main reason may be the difficulty to generalize this impact in the face of broad variability in responses among plant species, biomes and climates, as well as the variability introduced by methodology (Norby and Jackson, 2000). Our results call for further analyses on the role of site conditions (e.g. soil, altitude, topography and plant genotype) in determining tree responses to climate variability. An interesting next step would be to focus on better understanding how 
621 edaphic and climatic factors interact in natural environments to influence the fine root

622 phenology of plants at various temporal and spatial scales. In addition, the seasonal phenology

623 of trees is a main driver of $\mathrm{C}$ allocation from shoots to roots, thus further research is also

624 required to evaluate more precisely the relationship between the internal dynamics of tree C

625 and nutrient resources and root phenology.

626 Acknowledgments

627 Thanks are due to Jérôme Nespoulous, Luis Merino Martin and Merlin Ramel (INRA) for 628 technical assistance, to Camille Béral (Agroof) for help finding field sites and to the farmers 629 M. Queuille and M. Becue for letting us work in their agroforests.

\section{Competing interests}

631 The authors declare that they have no competing interests.

$632 \quad$ Funding

633 Funding for a Ph.D. bursary was provided by Campus France and the Kurdish Institute, France 634 (AM), la Fondation de France (YM) and fieldwork was funded by the FOARDAPT project, 635 INRA metaprogram AAFCC (Adaptation of Agriculture and Forests to Climate Change), 636 France. 


\section{References}

Abràmoff MD, Magalhães PJ, Ram SJ. 2004. Image processing with image. J Biophotonics Int 11

Abramoff RZ, Finzi AC. 2015. Are above- and below-ground phenology in sync? New Phytologist 205: 1054-61

Anderson L, Comas L, Lakso A, Eissenstat D. 2003. Multiple risk factors in root survivorship: A 4-year study in Concord grape. New Phytologist 158: 489-501

Baddeley JA, Watson CA. 2005. Influences of Root Diameter, Tree Age, Soil Depth and Season on Fine Root Survivorship in Prunus avium. Plant Soil 276: 15-22

Block RMA, Rees KCJ, Knight JD. 2006. A Review of Fine Root Dynamics in Populus Plantations. Agroforest Syst 67: 73-84

Blume-Werry G, Wilson SD, Kreyling J, Milbau A. 2016. The hidden season: growing season is 50\% longer below than above ground along an arctic elevation gradient. New Phytologist 209: 97886

Broschat TK. 1998. Root and shoot growth patterns in four palm species and their relationships with air and soil temperatures. HortScience 33: 995-98

Cardinael R, Mao Z, Prieto I, Stokes A, Dupraz C, et al. 2015. Competition with winter crops induces deeper rooting of walnut trees in a Mediterranean alley cropping agroforestry system. Plant Soil 391: 219-35

Chander K, Goyal S, Nandal PD, Kapoor KK. 1998. Soil organic matter, microbial biomass and enzyme activities in a tropical agroforestry system. Biology and Fertility of Soils 27: 168-72

Chen HY, Brassard BW. 2013. Intrinsic and extrinsic controls of fine root life span. Critical reviews in plant sciences 32: 151-61

Coll L, Camarero AJJ, Aragón JMD. 2012. Fine Root Seasonal Dynamics, Plasticity, and Mycorrhization in 2 Coexisting Mediterranean Oaks with Contrasting Aboveground Phenology. Ecoscience 19: 238-45

Contador ML, Comas LH, Metcalf SG, Stewart WL, Porris Gomez I, et al. 2015. Root growth dynamics linked to above-ground growth in walnut (Juglans regia). Ann Bot-London 116: 49-60

Cox T, Harris W, Ausmus B, Edwards N. 1977. The role of roots in biogeochemical cycles in eastern deciduous forests. The belowground Ecosystem: a Synthesis of Plant and associated Processes. Ed. JK Marshall: 321-26

Diez JM, Ibáñez I, Miller-Rushing AJ, Mazer SJ, Crimmins TM, et al. 2012. Forecasting phenology: from species variability to community patterns. Ecology letters 15: 545-53

Du E, Fang J. 2014. Linking belowground and aboveground phenology in two boreal forests in Northeast China. Oecologia 176: 883-92

Dupraz C, Fournier C, Balvay Y, Dauzat M, Pesteur S, Simorte V. Bois et Fôrets des Agriculteurs. Actes du colloque de Clermont-Ferrand des 1999, 20: 95-114. 
Fridley JD. 2012. Extended leaf phenology and the autumn niche in deciduous forest invasions. Nature 485: $359-62$

Fukuzawa K, Shibata H, Takagi K, Satoh F, Koike T, Sasa K. 2013. Temporal variation in fine-root biomass, production and mortality in a cool temperate forest covered with dense understory vegetation in northern Japan. Forest Ecology and Management 310: 700-10

Germon A, Cardinael R, Prieto I, Mao Z, Kim J, et al. 2016. Unexpected phenology and lifespan of shallow and deep fine roots of walnut trees grown in a silvoarable Mediterranean agroforestry system. Plant Soil 401: 409-26

Gill RA, Jackson RB. 2000. Global patterns of root turnover for terrestrial ecosystems. New Phytologist 147: 13-31

Green IJ, Dawson LA, Proctor J, Duff EI, Elston DA. 2005. Fine root dynamics in a tropical rain forest is influenced by rainfall. Plant Soil 276: 23-32

Guo D, Mitchell RJ, Withington JM, Fan P-P, Hendricks JJ. 2008. Endogenous and exogenous controls of root life span, mortality and nitrogen flux in a longleaf pine forest: root branch order predominates. Journal of Ecology 96: 737-45

Guo DL, Mitchell RJ, Hendricks JJ. 2004. Fine root branch orders respond differentially to carbon source-sink manipulations in a longleaf pine forest. Oecologia 140: 450-57

Harris JR, Bassuk NL, Zobel RW, Whitlow TH. 1995. Root and shoot growth periodicity of green ash, scarlet oak, turkish hazelnut, and tree lilac. J. Am. Soc. Hortic. Sci. 120: 211-16

Hendrick RL, Pregitzer KS. 1993a. The dynamics of fine root length, biomass, and nitrogen content in two northern hardwood ecosystems. Canadian Journal of Forest Research 23: 2507-20

Hendrick RL, Pregitzer KS. 1993b. Patterns of fine root mortality in 2 sugar maple forests. Nature 361: $59-61$

Hendrick RL, Pregitzer KS. 1996a. Applications of minirhizotrons to understand root function in forests and other natural ecosystems. Plant Soil 185: 293-304

Hendrick RL, Pregitzer KS. 1996b. Temporal and Depth-Related Patterns of Fine Root Dynamics in Northern Hardwood Forests. Journal of Ecology 84: 167-76

Hendricks JJ, Hendrick RL, Wilson CA, Mitchell RJ, Pecot SD, Guo D. 2006. Assessing the patterns and controls of fine root dynamics: an empirical test and methodological review. Journal of Ecology 94: 40-57

Heninger R, White D. 1974. Tree seedling growth at different soil temperatures. Forest Science 20: 36367

Hubbart J, Link T, Campbell C, Cobos D. 2005. Evaluation of a low-cost temperature measurement system for environmental applications. Hydrological Processes 19: 1517-23

Huck M, Hoogenboom G, Peterson CM. 1987. Soybean root senescence under drought stress. Minirhizotron observation tubes: methods and applications for measuring rhizosphere dynamics: $109-21$ 
Huck MG, Taylor HM. 1982. The Rhizotron as a Tool for Root Research In Advances in Agronomy, ed. NC Brady, pp. 1-35: Academic Press

Johnson MG. 2001. Advancing fine root research with minirhizotrons. Environ Exp Bot 45: 263-89

Joslin JD, Wolfe M. 1998. Impacts of Water Input Manipulations on Fine Root Production and Mortality in a Mature Hardwood Forest. Plant Soil 204: 165-74

Joslin JD, Wolfe MH, Hanson PJ. 2000. Effects of altered water regimes on forest root systems. New Phytologist 147: 117-29

Joslin JD, Wolfe MH, Hanson PJ. 2001. Factors controlling the timing of root elongation intensity in a mature upland oak stand. Plant Soil 228: 201-12

Jourdan C, Silva EV, Goncalves JLM, Ranger J, Moreira RM, Laclau JP. 2008. Fine root production and turnover in Brazilian Eucalyptus plantations under contrasting nitrogen fertilization regimes. Forest Ecology and Management 256: 396-404

Kahle H. 1993. Response of roots of trees to heavy metals. Environmental and Experimental Botany 33: 99-119

Kern CC, Friend AL, Johnson JM-F, Coleman MD. 2004. Fine root dynamics in a developing Populus deltoides plantation. Tree Physiology 24: 651-60

King J, Pregitzer K, Zak D. 1999. Clonal variation in above- and below-ground growth responses of Populus tremuloides Michaux: Influence of soil warming and nutrient availability. Plant Soil 217: $119-30$

Kuhns MR, Garrett HE, Teskey RO, Hinckley TM. 1985. Root-growth of black walnut trees related to soil-temperature, soil-water potential, and leaf water potential. Forest Science 31: 617-29

Lehmann J, Zech W. 1998. Fine root turnover of irrigated hedgerow intercropping in Northern Kenya. Plant Soil 198: 19-31

Lobet G, Pagès L, Draye X. 2011. A Novel Image-Analysis Toolbox Enabling Quantitative Analysis of Root System Architecture. Plant Physiology 157: 29-39

Lyr H. Annales des sciences forestières 1996, 53: 317-23. EDP Sciences.

M'bou AT, Jourdan C, Deleporte P, Nouvellon Y, St-Andre L, et al. 2008. Root elongation in tropical Eucalyptus plantations: effect of soil water content. Ann Forest Sci 65

McCormack M, Adams TS, Smithwick EAH, Eissenstat DM. 2012. Predicting fine root lifespan from plant functional traits in temperate trees. New Phytologist 195: 823-31

Majdi H. 1996. Root sampling methods - applications and limitations of the minirhizotron technique. Plant Soil 185: 255-58

Majdi H, Pregitzer K, Morén A-S, Nylund J-E, I. Ågren G. 2005. Measuring Fine Root Turnover in Forest Ecosystems. Plant Soil 276: 1-8

Mao Z, Bonis M-L, Rey H, Saint-André L, Stokes A, Jourdan C. 2013a. Which processes drive fine root elongation in a natural mountain forest ecosystem? Plant Ecology \& Diversity 6: 231-43 
Mao Z, Bonis ML, Rey H, Saint-Andre L, Stokes A, Jourdan C. 2013b. Which processes drive fine root elongation in a natural mountain forest ecosystem? Plant Ecology \& Diversity 6: 231-43

Mao Z, Jourdan C, Bonis M-L, Pailler F, Rey H, et al. 2013c. Modelling root demography in heterogeneous mountain forests and applications for slope stability analysis. Plant Soil 363: $357-82$

Mapelli S, Lombardi L, Brambilla I, Iulini A, Bertani A. III International Walnut Congress 4421995: 129-36.

Mathieu L, Lobet G, Tocquin P, Périlleux C. 2015. "Rhizoponics": a novel hydroponic rhizotron for root system analyses on mature Arabidopsis thaliana plants. Plant Methods 11: 1-8

McAdam SAM, Brodribb TJ, Ross JJ. 2016. Shoot-derived abscisic acid promotes root growth. Plant, Cell \& Environment 39: 652-59

McCormack ML, Adams TS, Smithwick EAH, Eissenstat DM. 2014. Variability in root production, phenology, and turnover rate among 12 temperate tree species. Ecology 95: 2224-35

McCormack ML, Guo D. 2014. Impacts of environmental factors on fine root lifespan. Front Plant Sci 5: 205

Menzel A. 2003. Plant Phenological Anomalies in Germany and their Relation to Air Temperature and NAO. Climatic Change 57: 243-63

Metcalfe DB, Meir P, Aragão LEO, da Costa AC, Braga AP, et al. 2008. The effects of water availability on root growth and morphology in an Amazon rainforest. Plant Soil 311: 189-99

Misra RK. 1999. Root and shoot elongation of rhizotron-grown seedlings of Eucalyptus nitens and Eucalyptus globulus in relation to temperature. Plant Soil 206: 37-46

Misson L, Gershenson A, Tang J, McKay M, Cheng W, Goldstein A. 2006. Influences of canopy photosynthesis and summer rain pulses on root dynamics and soil respiration in a young ponderosa pine forest. Tree Physiology 26: 833-44

Mohamed A, Monnier Y, Mao Z, Lobet G, Maeght J-L, et al. 2017. An evaluation of inexpensive methods for root image acquisition when using rhizotrons. Plant Methods 13: 11

Morin X, Roy J, Sonié L, Chuine I. 2010. Changes in leaf phenology of three European oak species in response to experimental climate change. New Phytologist 186: 900-10

Mulia R, Dupraz C. 2006. Unusual Fine Root Distributions of Two Deciduous Tree Species in Southern France: What Consequences for Modelling of Tree Root Dynamics? Plant Soil 281: 71-85

Pregitzer KS, King JS, Burton AJ, Brown SE. 2000. Responses of tree fine roots to temperature. New Phytologist 147: 105-15

Psarras G, Merwin IA, Lakso AN, Ray JA. 2000. Root Growth Phenology, Root Longevity, and Rhizosphere Respiration of Field Grown Mutsu'Apple Trees on Malling Rootstock. J. Am. Soc. Hortic. Sci. 125: 596-602

Radville L, McCormack ML, Post E, Eissenstat DM. 2016a. Root phenology in a changing climate. Journal of Experimental Botany 
Radville L, Post E, Eissenstat DM. 2016b. Root phenology in an Arctic shrub-graminoid community: the effects of long-term warming and herbivore exclusion. Climate Change Responses 3: 1-9

Ramachandran Nair P, Mohan Kumar B, Nair VD. 2009. Agroforestry as a strategy for carbon sequestration. Journal of Plant Nutrition and Soil Science 172: 10-23

Reich P, Teskey R, Johnson P, Hinckley T. 1980. Periodic root and shoot growth in oak. Forest Science 26: $590-98$

Richardson AD, Bailey AS, Denny EG, Martin CW, O'Keefe J. 2006. Phenology of a northern hardwood forest canopy. Global Change Biology 12: 1174-88

Sloan VL, Fletcher BJ, Phoenix GK. 2016. Contrasting synchrony in root and leaf phenology across multiple sub-Arctic plant communities. Journal of Ecology 104: 239-48

Solomon S, Qin D, Manning M, Chen Z, Marquis M, et al. 2007. Contribution of working group I to the fourth assessment report of the intergovernmental panel on climate change, 2007. Cambridge University Press, Cambridge

Steinaker DF, Wilson SD. 2008. Phenology of fine roots and leaves in forest and grassland. Journal of Ecology 96: 1222-29

Steinaker DF, Wilson SD, Peltzer DA. 2010. Asynchronicity in root and shoot phenology in grasses and woody plants. Global Change Biology 16: 2241-51

Tanner SC, Reighard GL, Wells CE. 2006. Soil treatments differentially affect peach tree root development and demography in a replant site In Proceedings of the VIth International Peach Symposium, ed. R Infante, pp. 381-87

Tierney GL, Fahey TJ. 2002. Fine root turnover in a northern hardwood forest: a direct comparison of the radiocarbon and minirhizotron methods. Canadian Journal of Forest Research 32: 1692-97

Vogt K, Vogt D, Palmiotto P, Boon P, O'Hara J, Asbjornsen H. 1995. Review of root dynamics in forest ecosystems grouped by climate, climatic forest type and species. Plant Soil 187: 159-219

Vogt KA, Grier CC, Vogt DJ. 1986. Production, turnover and nutrient dynamics of above and belowground detritus of world forests. Adv Ecol Res 15

Vogt KA, Vogt DJ, Bloomfield J. 1998. Analysis of some direct and indirect methods for estimating root biomass and production of forests at an ecosystem level In Root Demographics and Their Efficiencies in Sustainable Agriculture, Grasslands and Forest Ecosystems, ed. J Box, Jr., pp. 687-720: Springer Netherlands

Wan CG, Yilmaz I, Sosebee RE. 2002. Seasonal soil-water availability influences snakeweed, root dynamics. Journal of Arid Environments 51: 255-64

Wang Z, Ding L, Wang J, Zuo X, Yao S, Feng J. 2016. Effects of root diameter, branch order, root depth, season and warming on root longevity in an alpine meadow. Ecological Research 31: 739-47

Wells CE, Eissenstat DM. 2001. Marked differences in survivorship among apple roots of different diameters. Ecology 82: 882-92 
823 West JB, Espeleta JF, Donovan LA. 2004. Fine root production and turnover across a complex edaphic gradient of a Pinus palustris-Aristida stricta savanna ecosystem. Forest Ecology and Management 189: 397-406

826 Wielgolaski F-E. 1999. Starting dates and basic temperatures in phenological observations of plants.

827 International Journal of Biometeorology 42: 158-68

828

829

830 
832 7. Figures

833

Comment citer ce document :

Mohamed, A. Stokes, A., Mao, Z., Jourdan, C., Sabatier, S., Pailler, F Fourtier S, Dufour,

L., Monnier, Y. (2018). Linking above- and belowground phenology of hybrid walnut growing along a climatic gradient in temperate agroforestry systems. Plant and Soil, 424 (1-2), 103-122. 
Comment citer ce document :

Mohamed, A. Stokes, A., Mao, Z., Jourdan, C., Sabatier, S.,Pailler, F., Fourtier, S., Dufour, L., Monnier, Y. (2018). Linking above- and belowground phenology of hybrid walnut growing along a climatic gradient in temperate agroforestry systems. Plant and Soil, 424 (1-2), 103-122. 


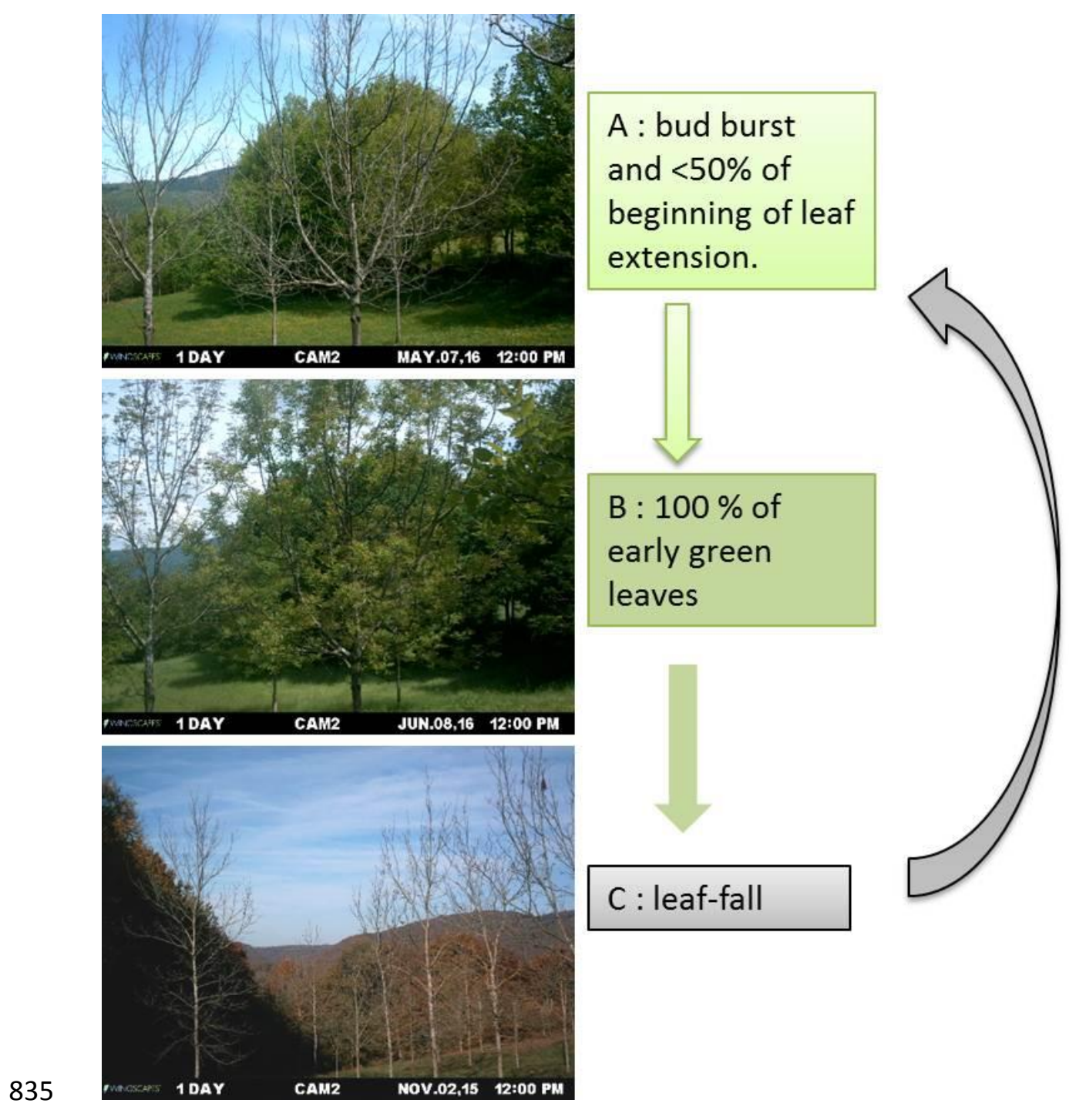

836 Figure 1. The three leaf phenological phases observed throughout the year (bud-burst, 100\% leafing, 837 leaf-fall). 

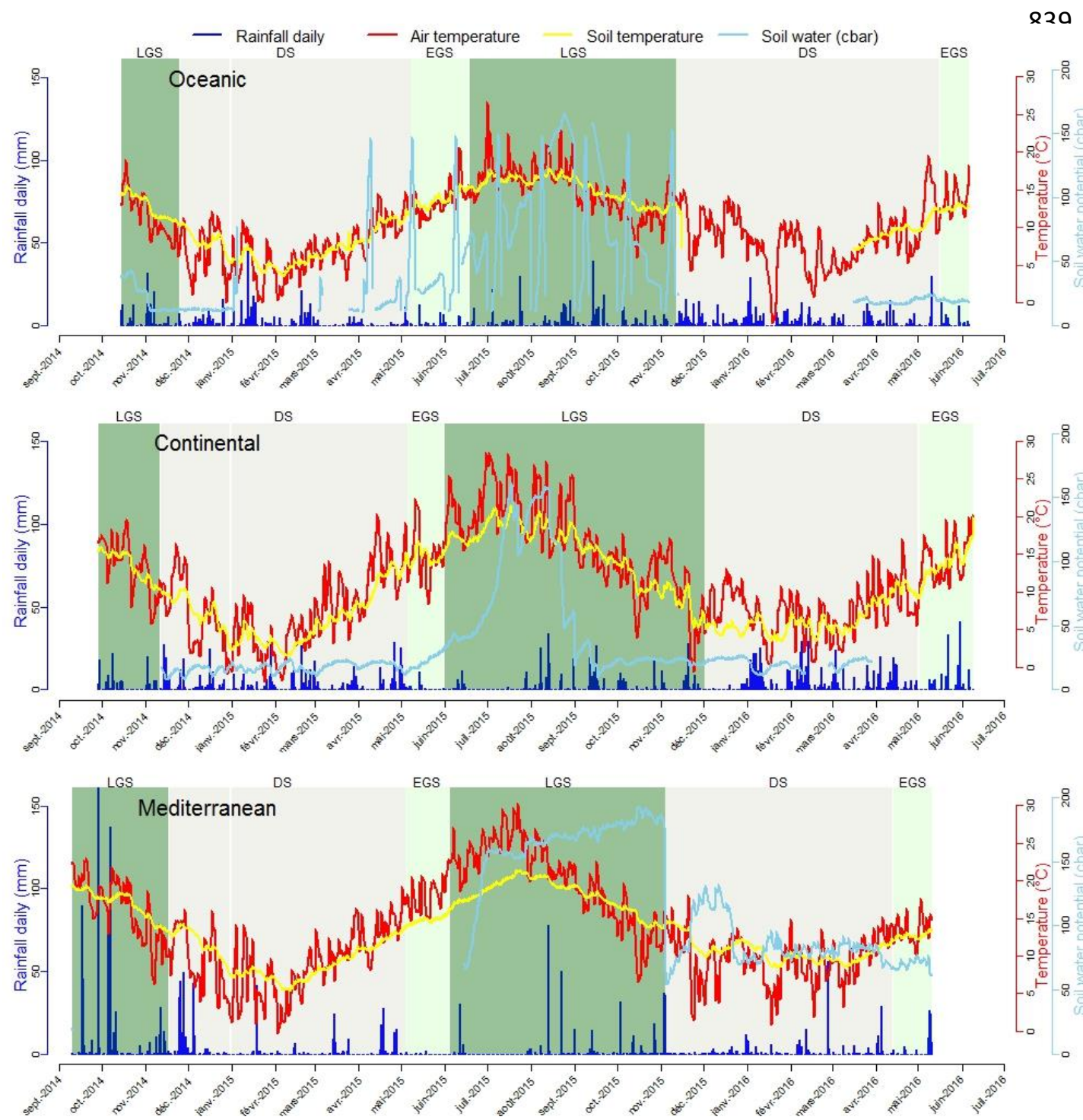

856

857 Fig 2. Soil (yellow line) and air (red line; measured at a height of $1.5 \mathrm{~m}$ above rhizotrons)

858 temperatures, daily precipitation (blue bars) and soil water potential (light blue line) at a)

859 oceanic, b) continental and c) Mediterranean field sites over the observation period from

860 September 2014 to June 2016. Different background colors correspond to different

861 phenological periods: "LGS" is late growing season (green) "EGS" is early growing season

862 (light green), "DS" is dormant season (gray). 


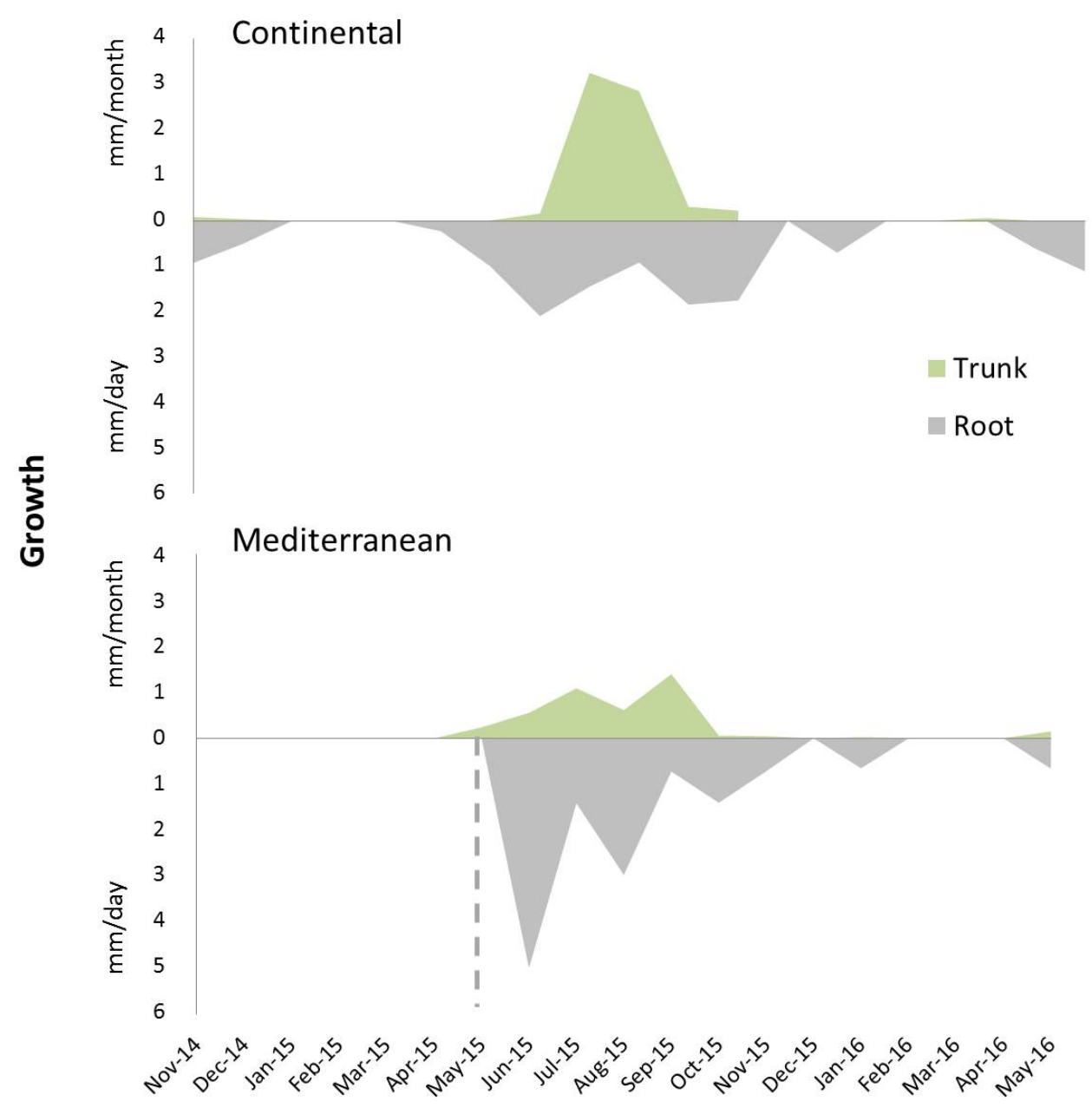

878 Fig 3: Comparison of root elongation rate (RER, grey area) and trunk radial (green area) growth 879 peaks in Mediterranean and Continental sites, over the observation period from November 2014 880 to May 2016. The starting date for RER measurements in Mediterranean site is shown with a 881 vertical dotted line. Detailed stem radial growth data are not available for the oceanic site. 


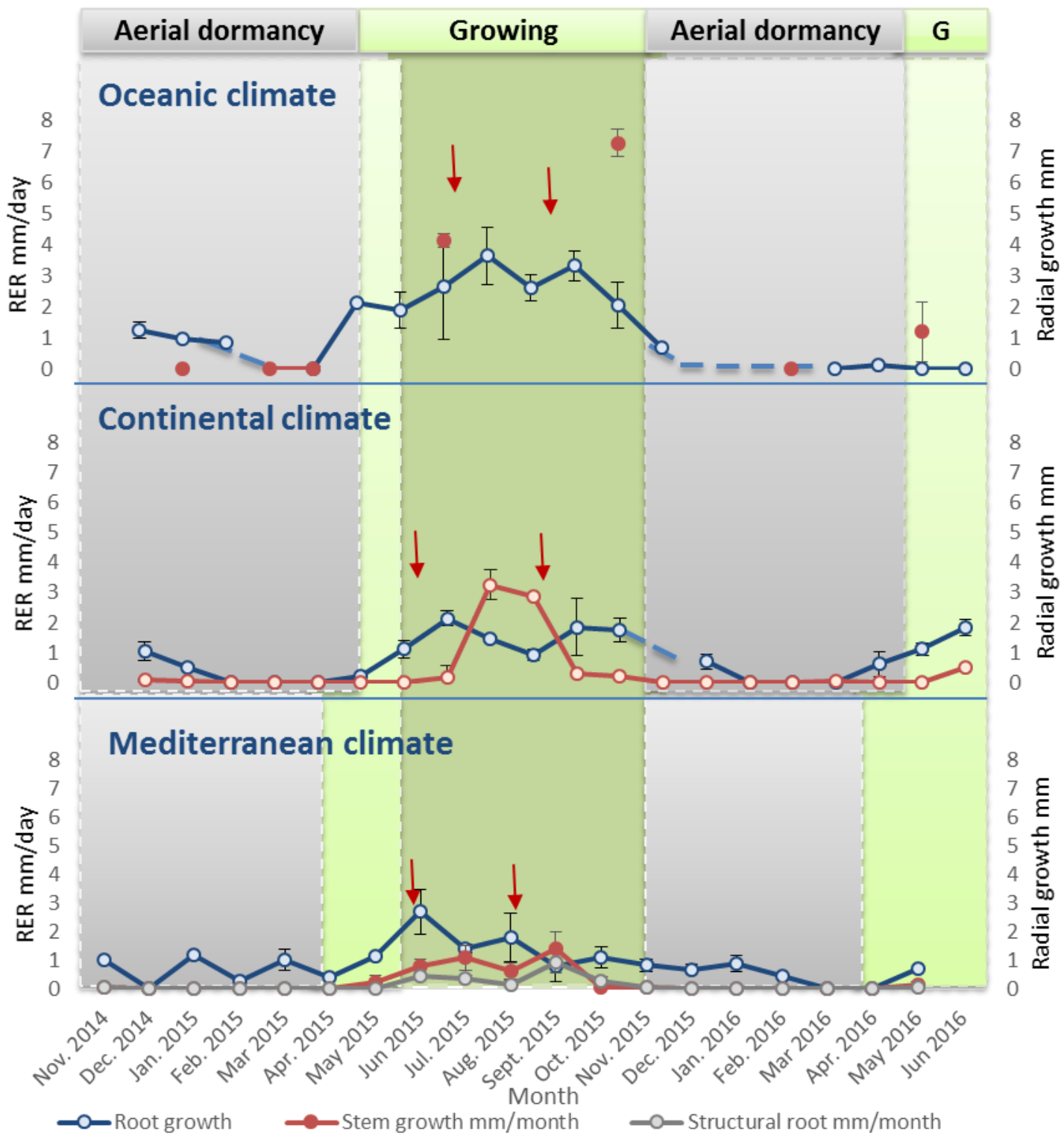

883

Fig. 4. Mean root elongation rate (RER, blue line) and trunk radial growth (red line) at a) oceanic, b) continental and c) Mediterranean field sites over the observation period from September 2014 to June 2016. Different background colours correspond to different phenological periods: "LGS" is late growing season (green) "EGS" is early growing season (light green), "DS" is dormant season (gray). Missing data/ flood damage is shown with a dotted line over the dashed curves. Vertical bars represent standard deviations (not shown when smaller than the symbol size). 


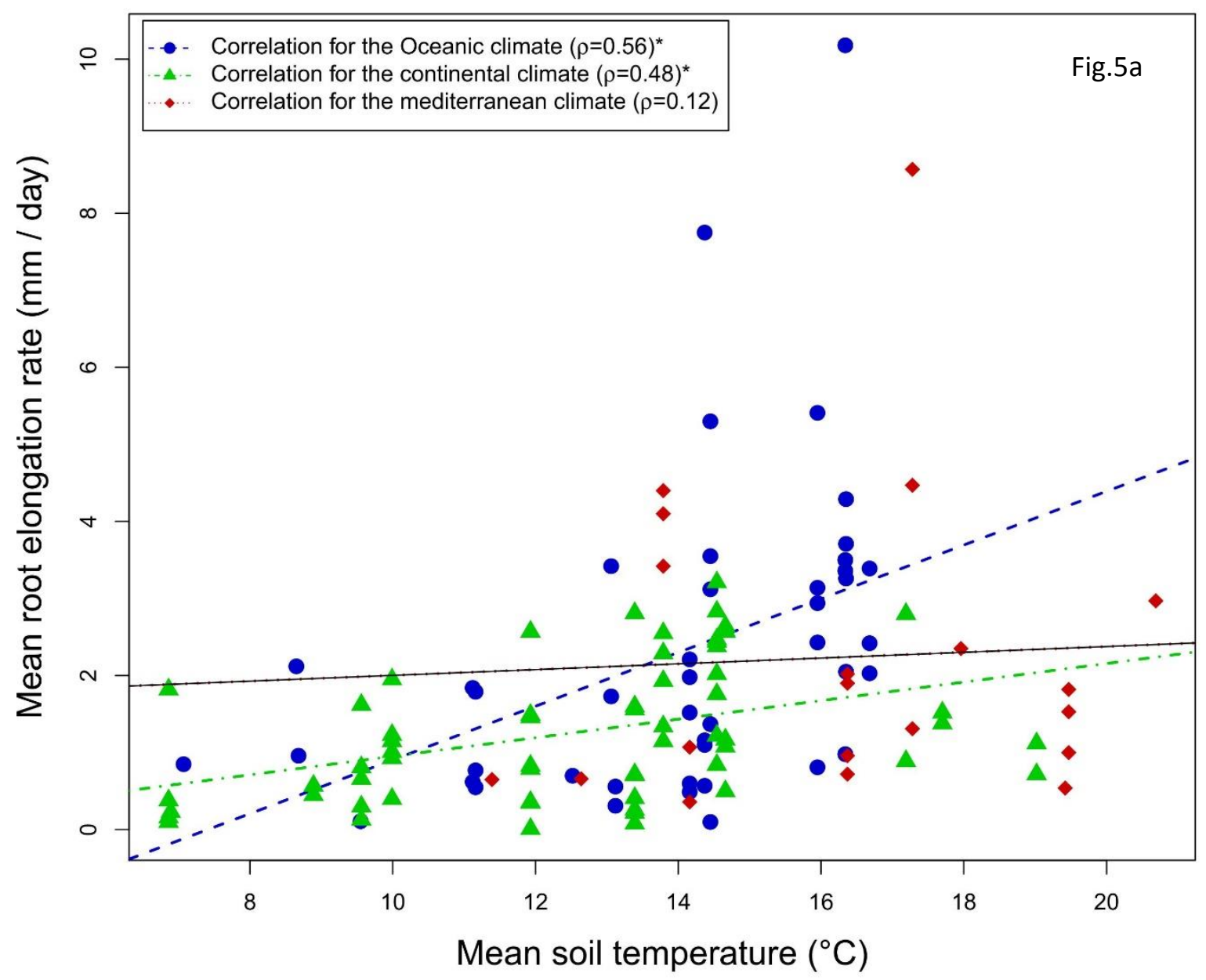

892 


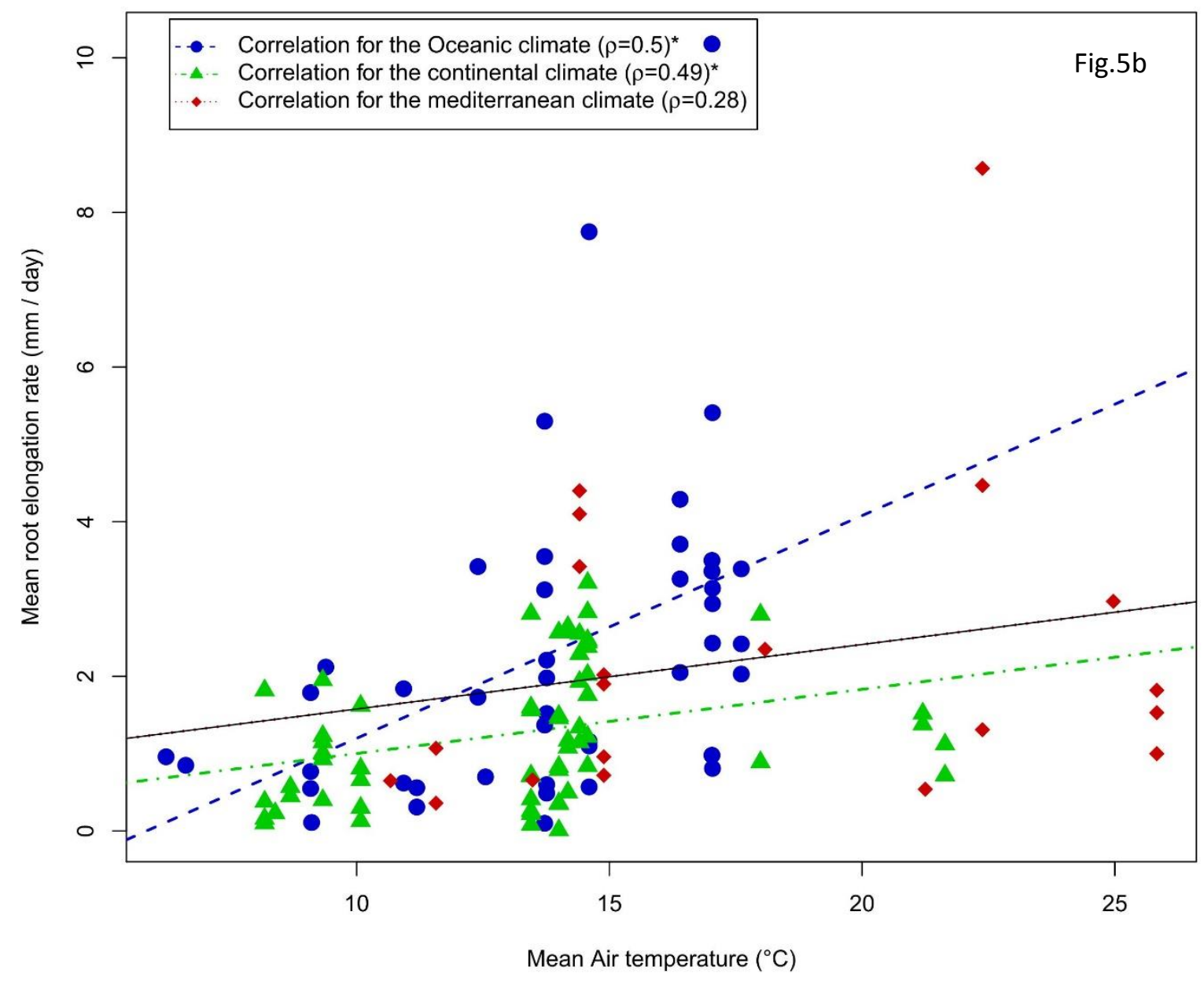

893 


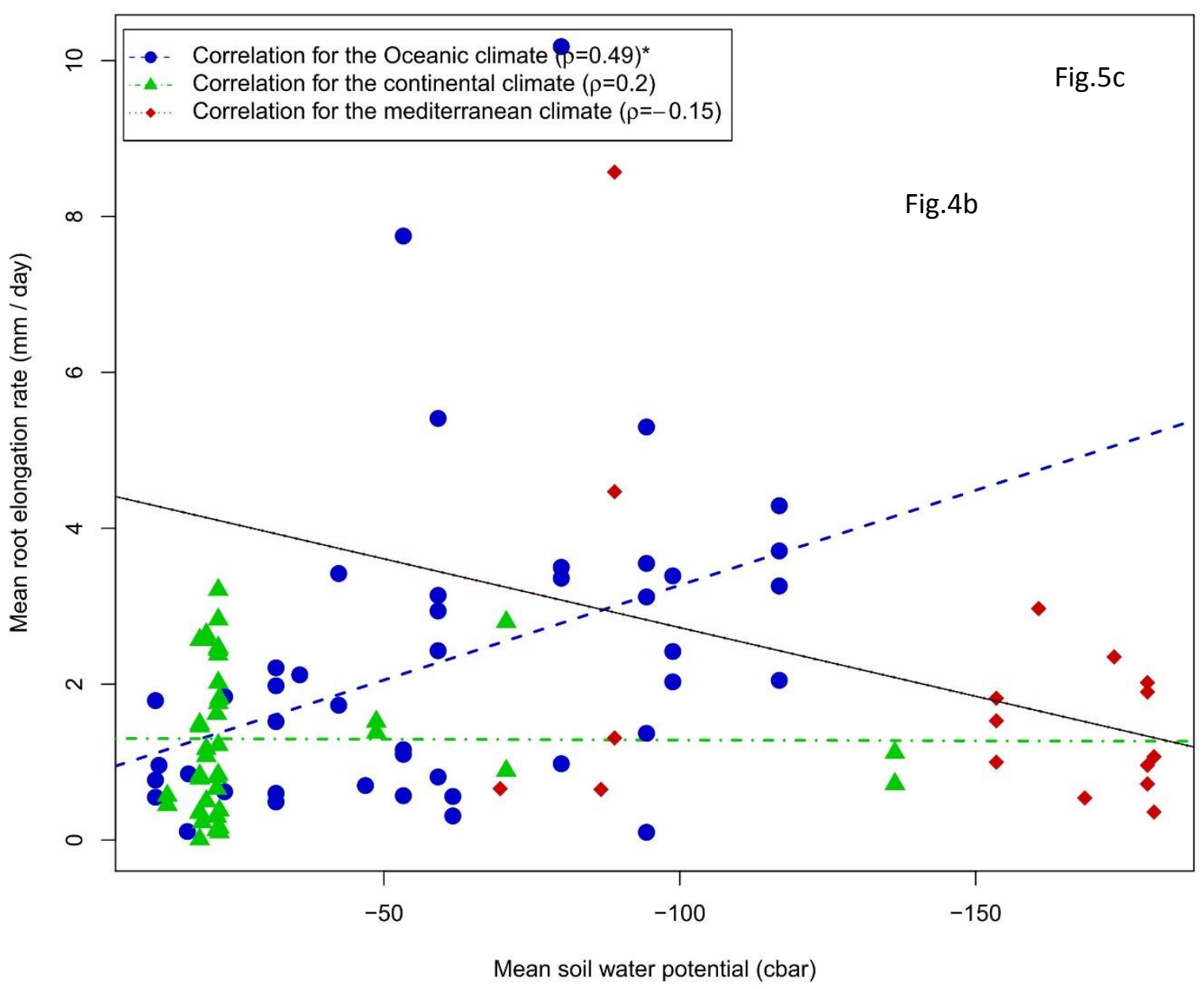

894

895 Fig 5: Correlations (for all periods combined together) between mean root elongation rate 896 (RER) and (a) mean soil temperature, (b) mean air temperature and (c) mean soil water potential 897 at the oceanic (green triangles and dot-dashed line), continental (blue circles and dashed line) 898 and Mediterranean (red diamonds and dotted line) sites.

899 


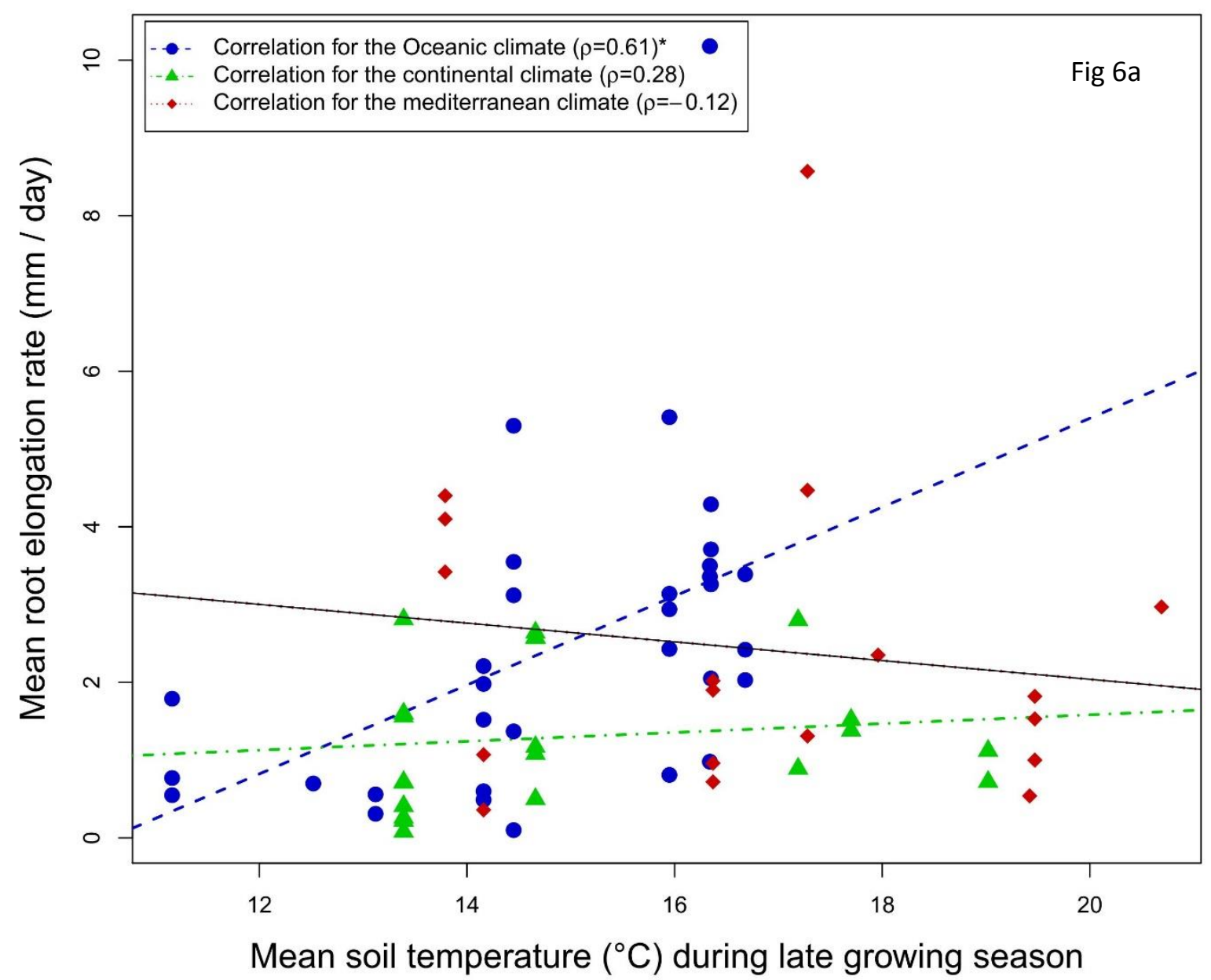

901 


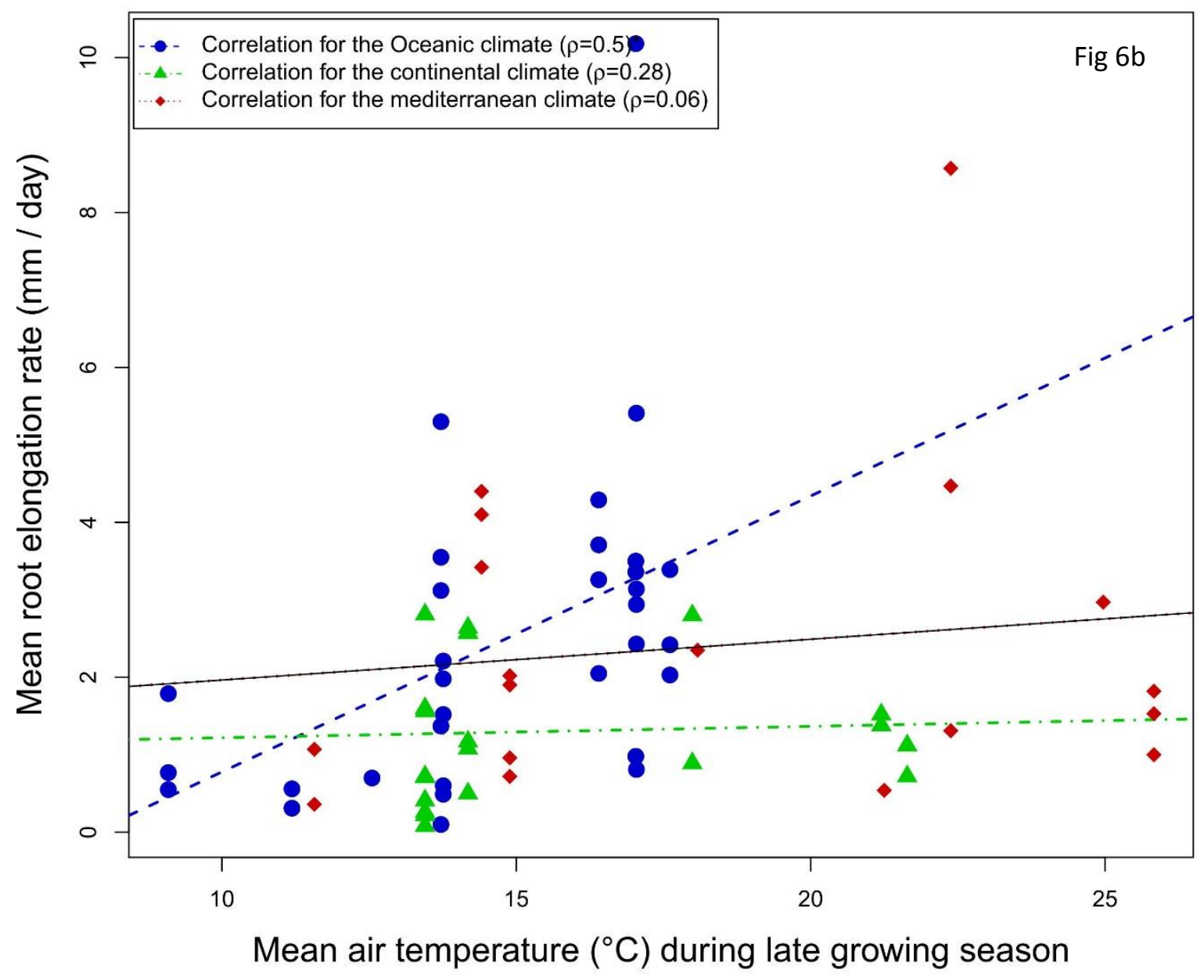

902 


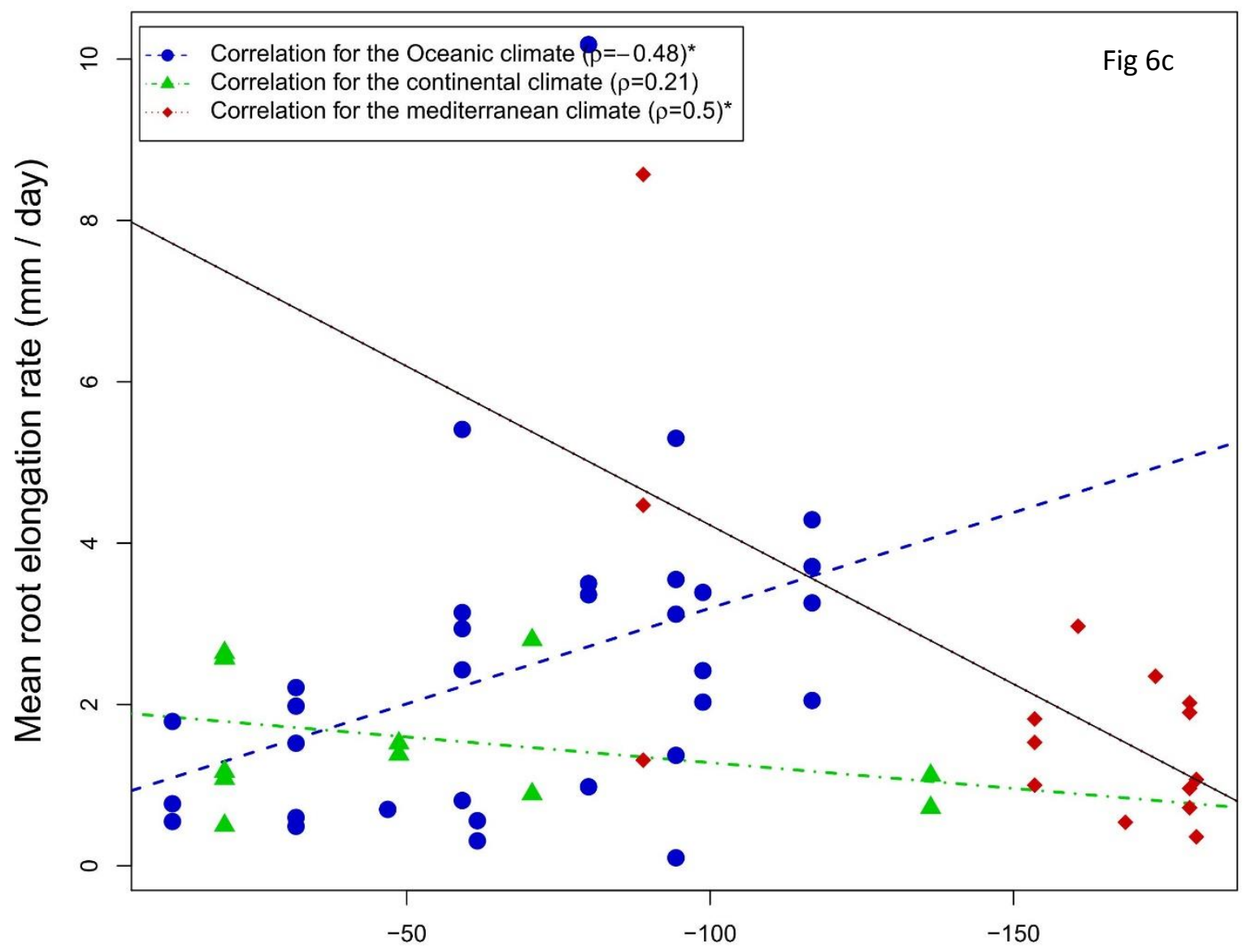

Mean soil water potential (cbar)during late growing season

905 Fig 6. Correlations (for late growing season only) between mean root elongation rate (RER) 906 and (a) mean soil temperature, (b) mean air temperature and (c) mean soil water potential at the 907 oceanic (green triangles and dotdash line), continental (blue circles and dashed line) and 908 Mediterranean (red diamonds and dotted line) sites. Vertical bars represent standard deviations 909 (not shown when smaller than the symbol size). 


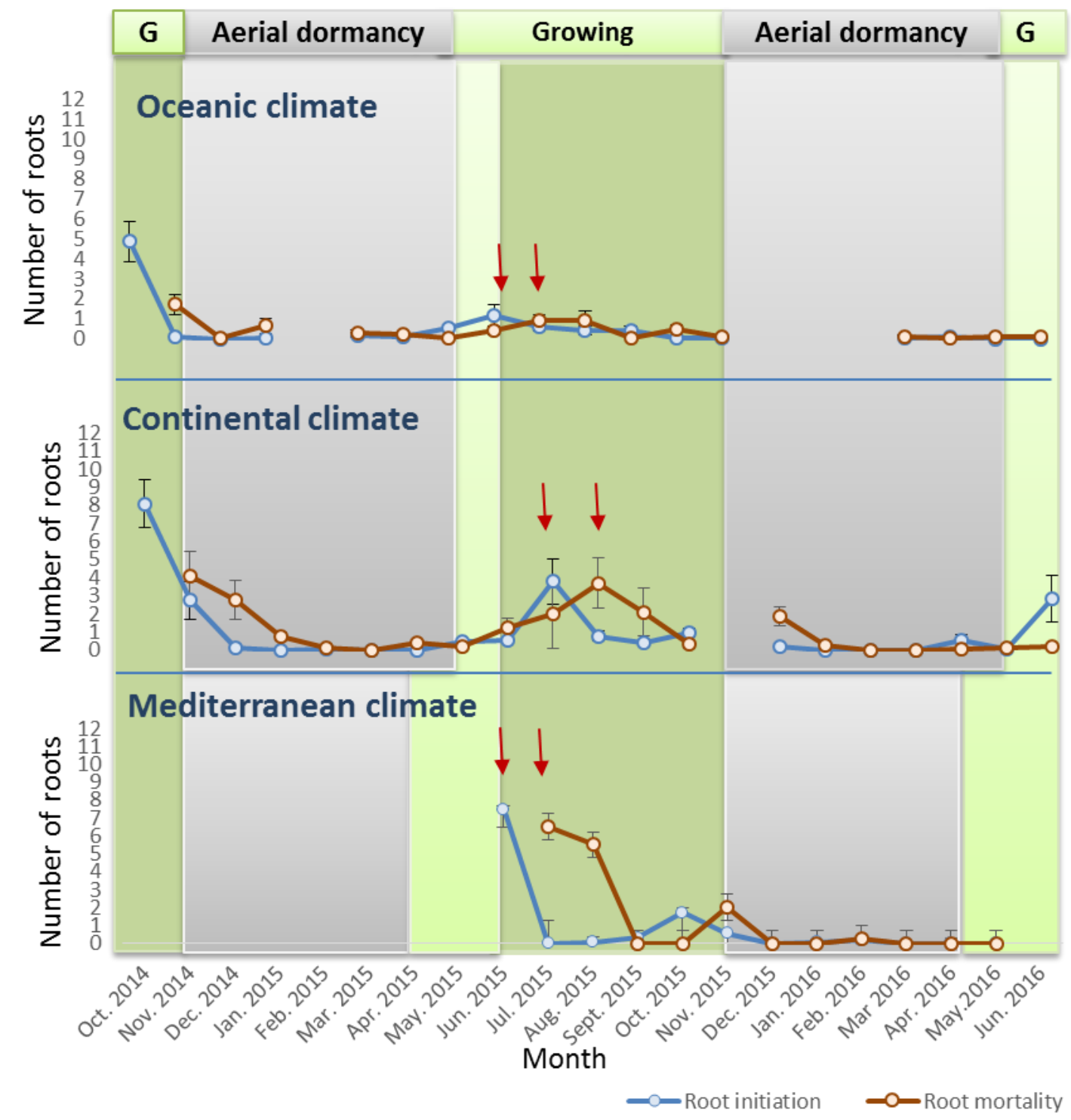

912 Fig 7. Mean root initiation quantity (RIQ, blue line) and mean root mortality quantity (RMQ,

913 red line) between time $t_{\text {and }} t_{-1}$, per $0.25 \mathrm{~m}^{-2}$ rhizotron (red line) at a) oceanic, b) continental 914 and c) Mediterranean field sites over the observation period from September 2014 to June 2016.

915 Different background colors correspond to different phenological periods: "LGS" is late 916 growing season (green) "EGS" is early growing season (light green), "DS" is dormant season 917 (gray). Missing data/ flood damage is shown with a dotted line over the dashed curves. 


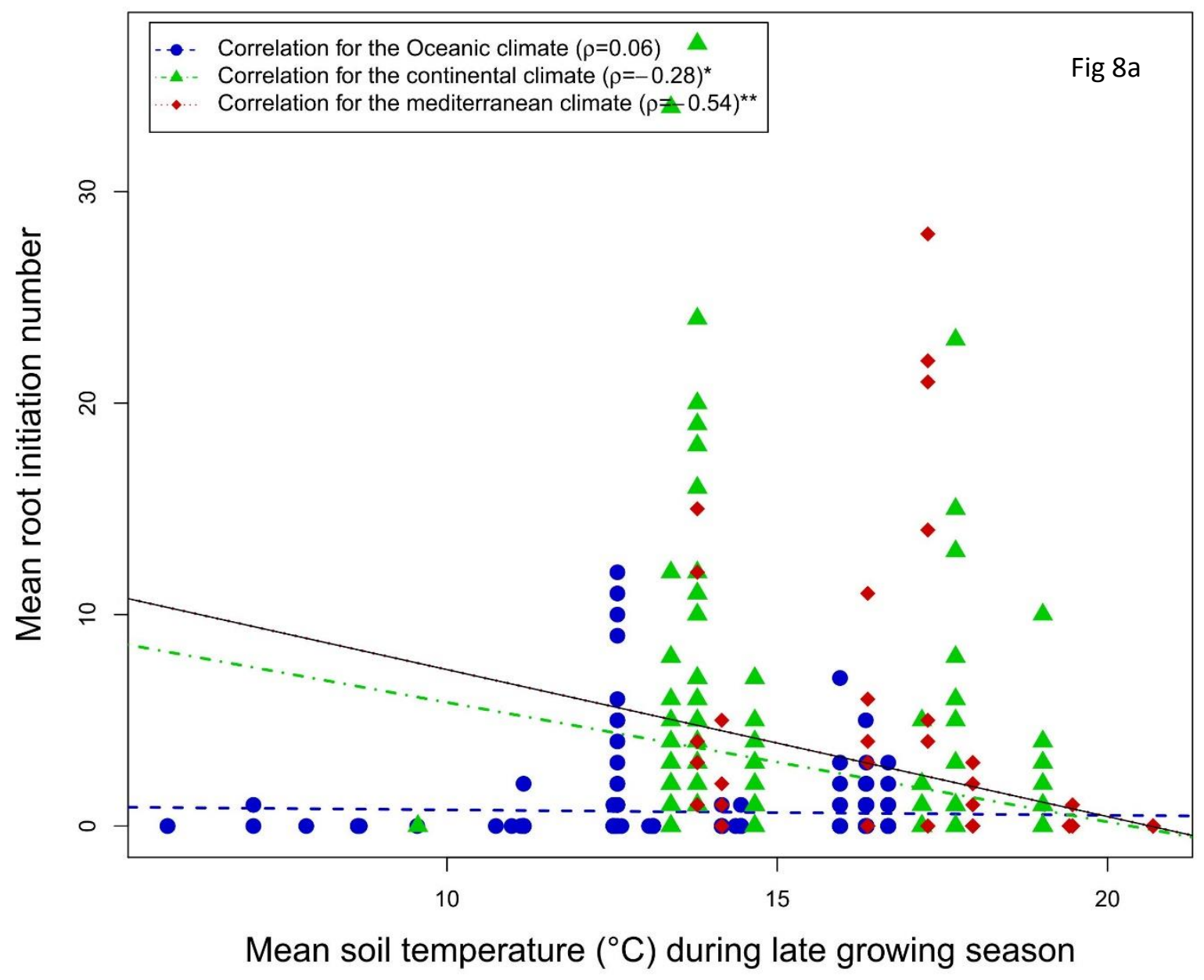

919

920

921 


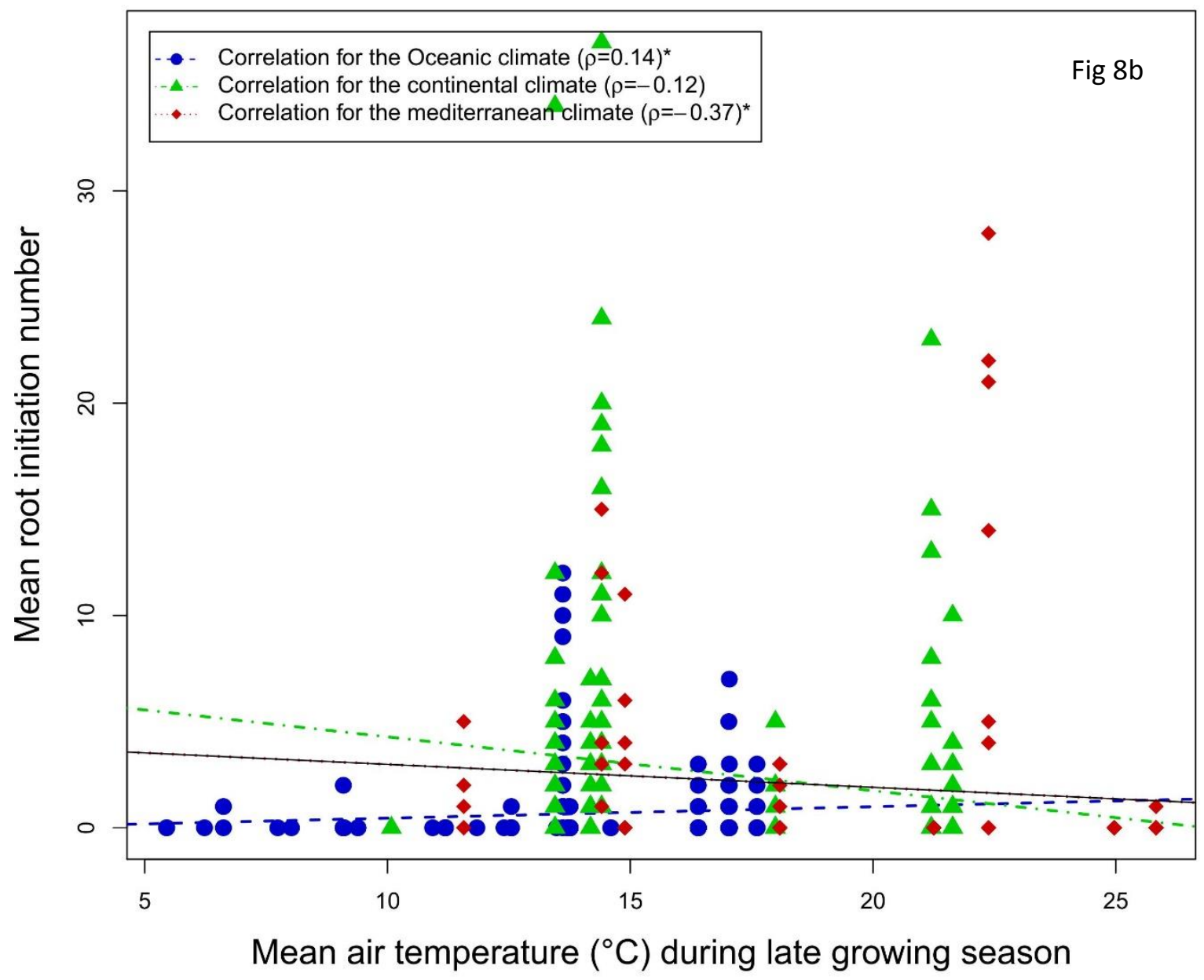




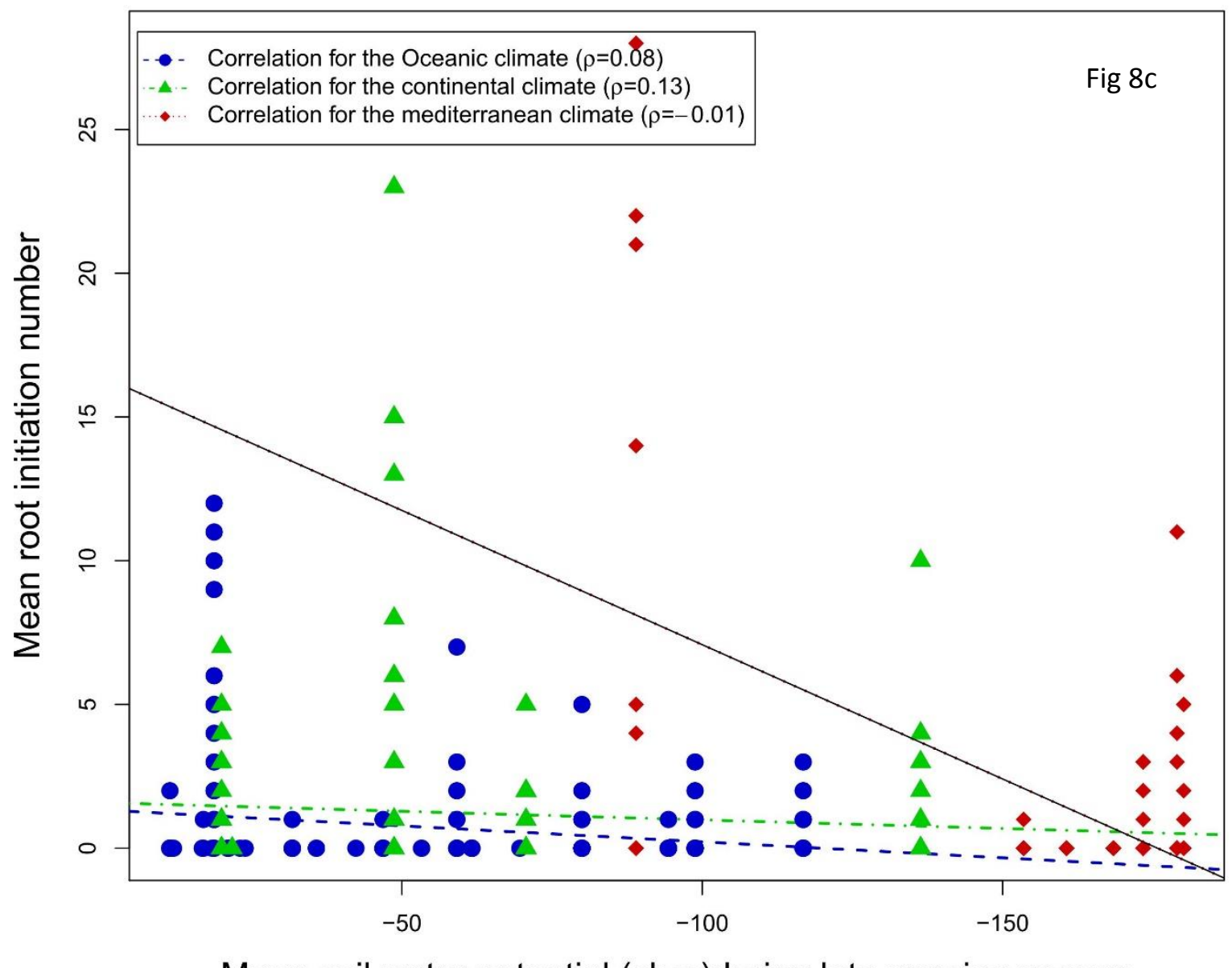

Mean soil water potential (cbar)during late growing season

Fig 8. Correlations (for late growing season only) between mean root initiation (RIQ) and (a) mean soil temperature, (b) mean air temperature and (c) mean soil water potential at the oceanic

927 (green triangles and solid line), continental (blue circles and dotted line) and Mediterranean 928 (red diamonds and dashed line) sites. 


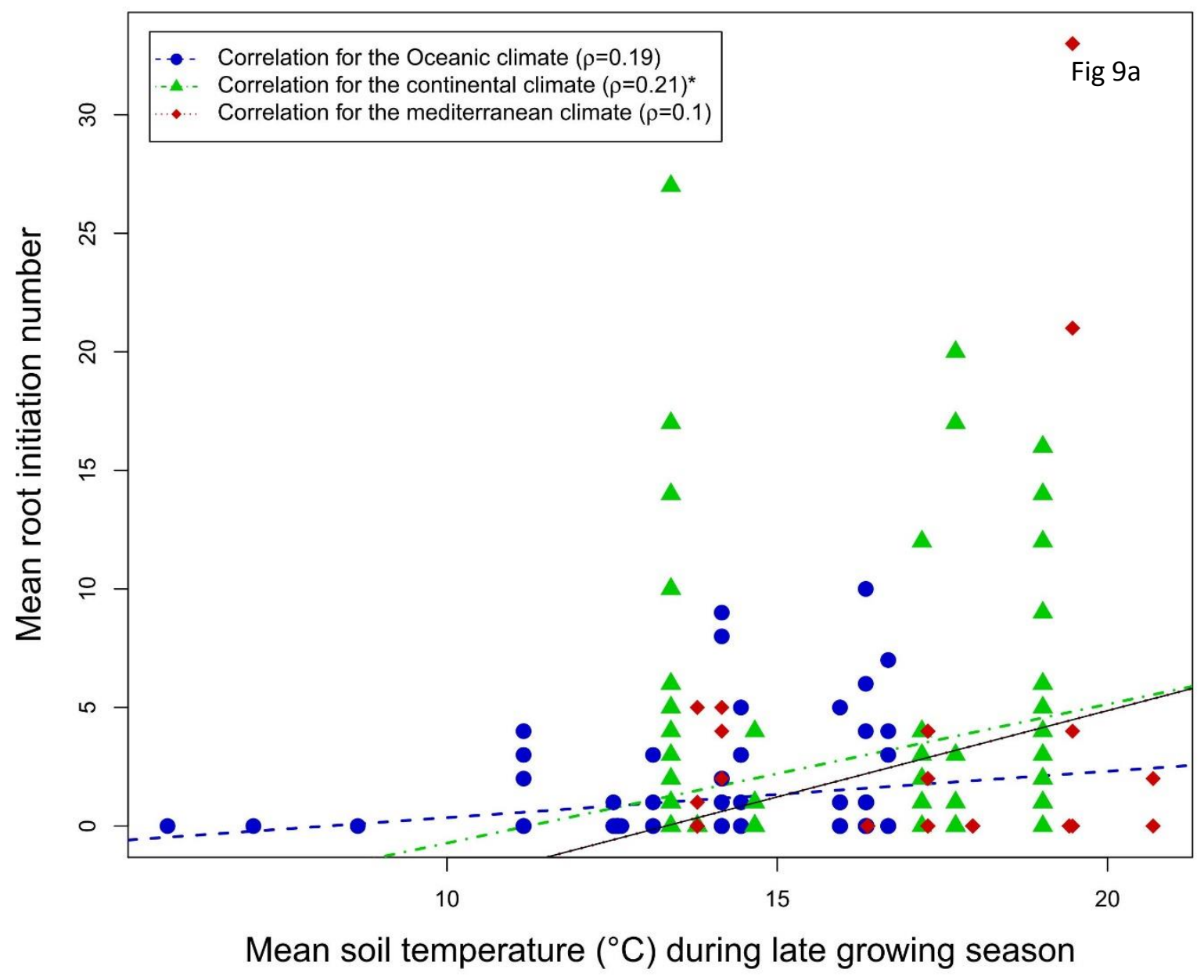

933

934

935 


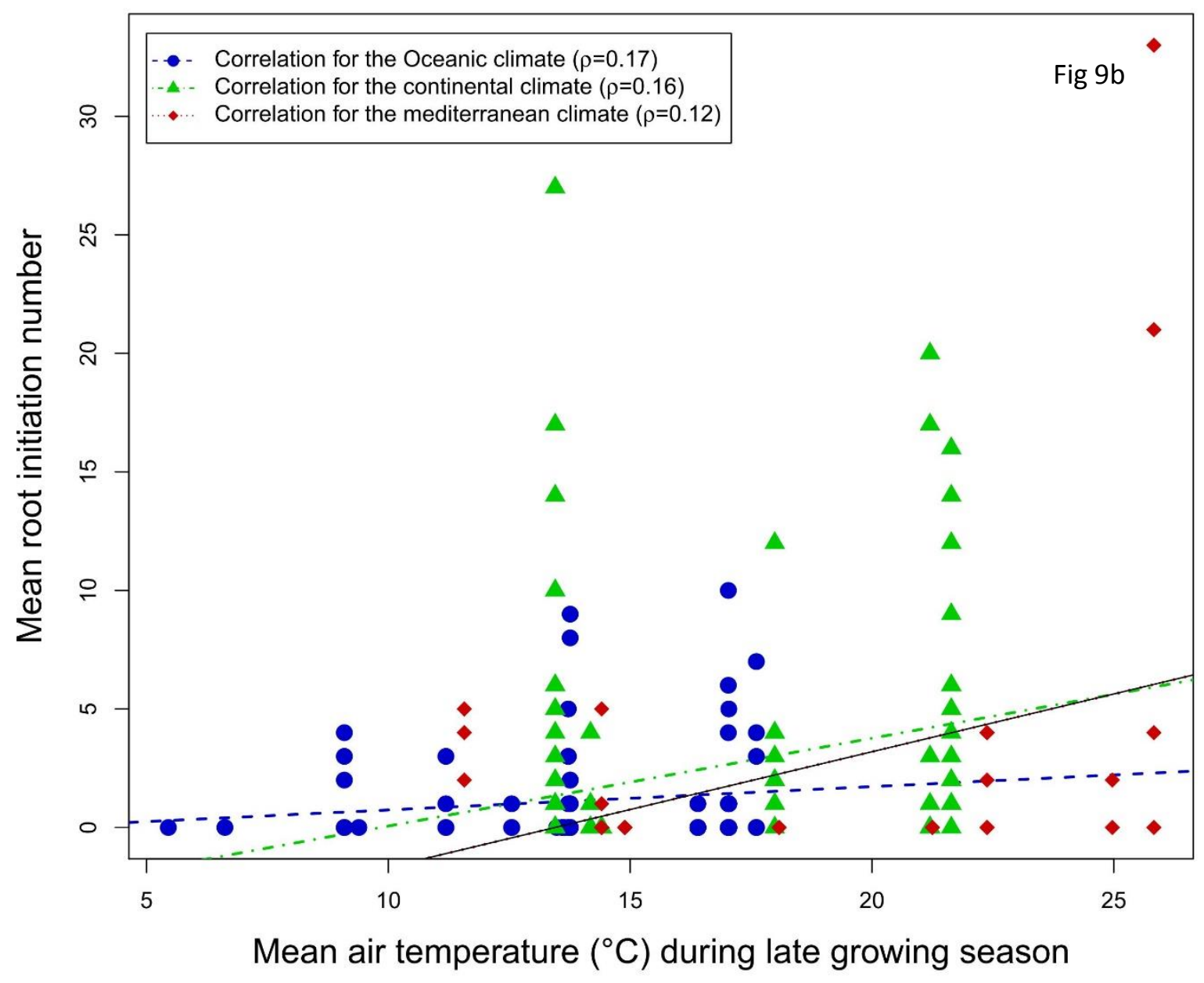

936

937 


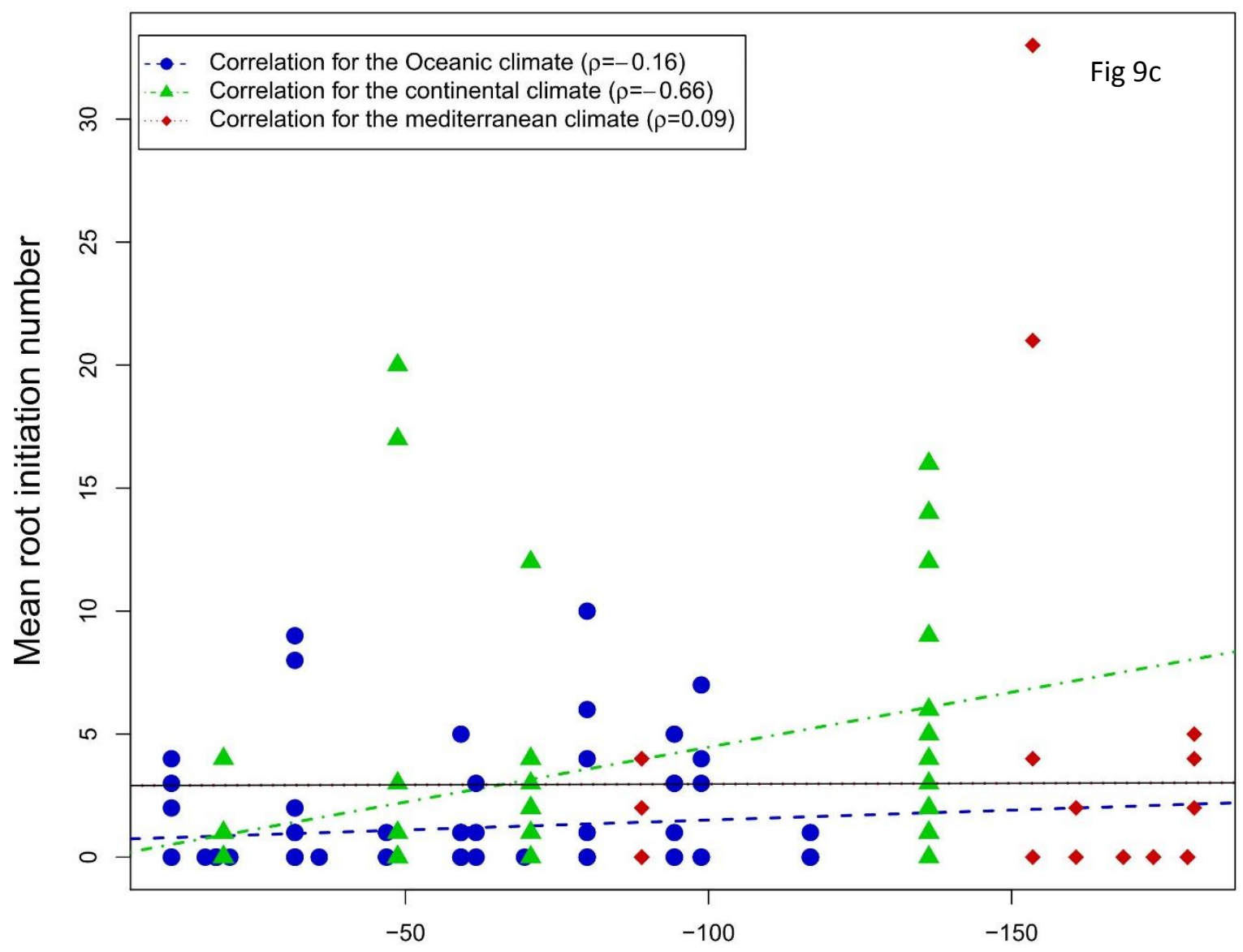

Mean soil water potential (cbar)during late growing season

941 Fig 9. Correlations (for late growing season only) between mean root mortality (RMQ) and (a)

942 mean soil temperature, (b) mean soil water potential at the oceanic (green triangles and solid

943 line), continental (blue circles and dotted line) and Mediterranean (red diamonds and dashed

944 line) sites. 


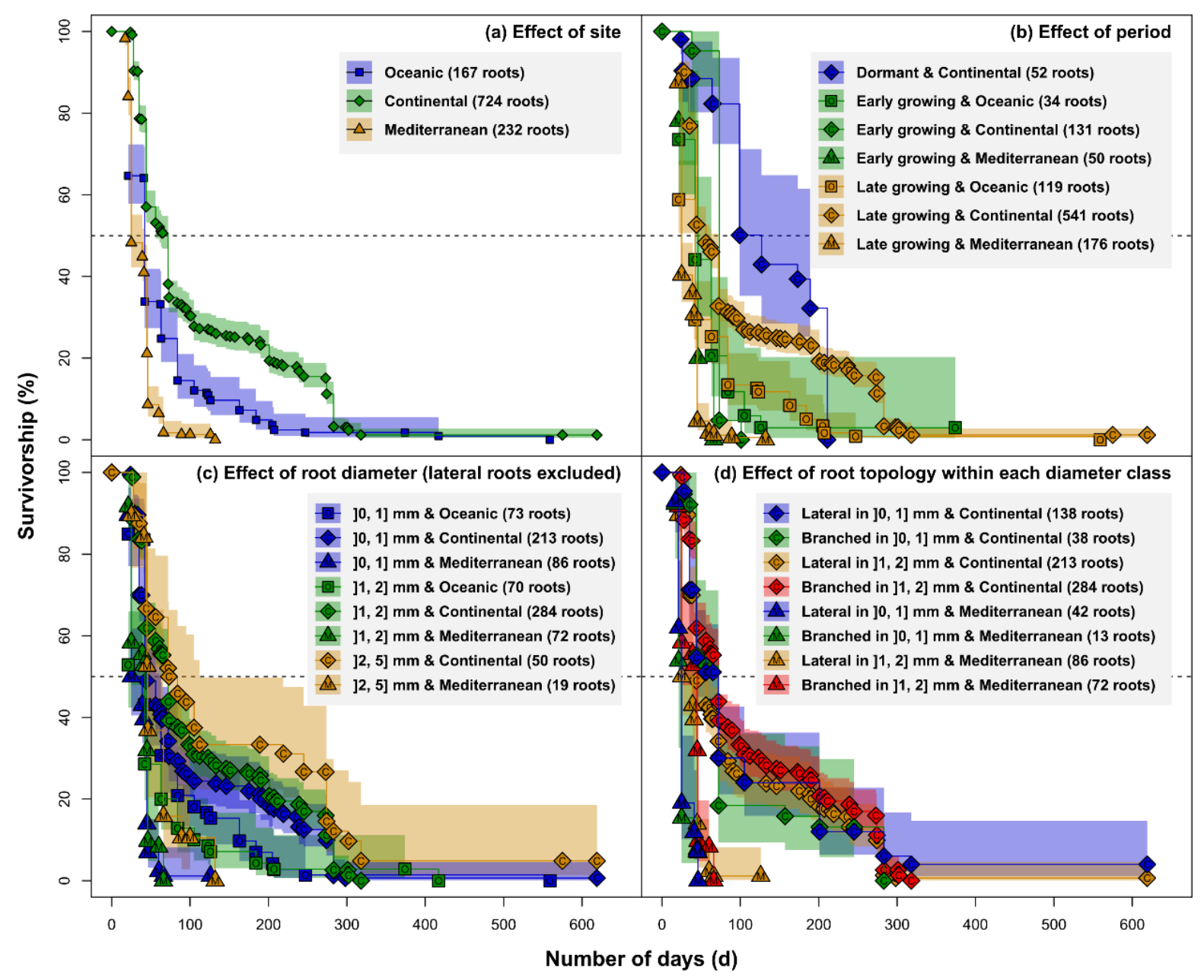

949

950

951 Fig 10. Cox's hazard regression relationships for estimating root longevity and risk of mortality

952 in relation to (a) climate (oceanic - squares, continental - diamonds and Mediterranean -

953 triangles), (b) phenological periods (early growing season, late growing season and dormant

954 season), (c) root diameter classes (0-1) $\mathrm{mm},(1-2) \mathrm{mm}$ and (2-5) $\mathrm{mm}$ and (d) root topological

955 order (first and second order roots) over the observation period from October 2014 to June

956 2016. Different shades represent the interval confidence of each curve corresponding to the

957 color of that curve. 
959 Table 1: Soil physical and chemical characteristics at each site. Data are means \pm standard 960 deviation (S.D.)

\section{Soil properties}

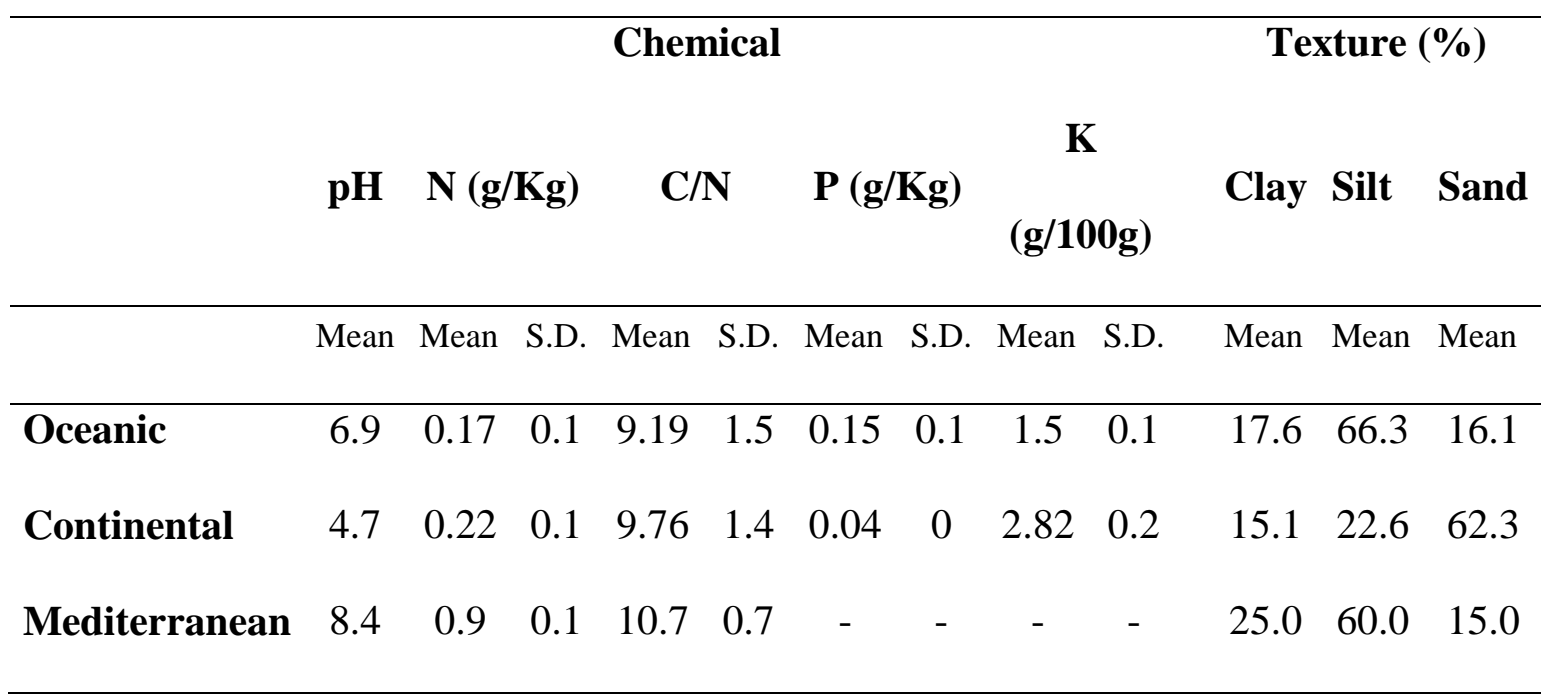

961

962 
963 Table 2. The length (in days) of different phases of the growing season for both shoots and roots

964 in the three climates

\begin{tabular}{lllll}
\hline Phenological & Early growing & Late growing & Dormant season & Total growing \\
growth periods & season & season & & season
\end{tabular}

\section{Shoot}

Year

$2015 \quad 2016 \quad 2015$

2014- 2015- 2015

$2015 \quad 2016$

Oceanic

$\begin{array}{lllllll}\text { Date } & 15 \text { May } & \text { 12 May } & 18 \text { Jun } & & 08 \text { Nov } & 03 \\ \text { Length } & 34 & - & 138 & 188 & \text { Nov } & 172\end{array}$

191

\section{Continental}

Date

3 May 5 May 05 Jun

$12 \mathrm{Nov} 28 \mathrm{Oct}$

Length

$33 \quad 36$

145

172

190

178

\section{Mediterranean}

Date

18 Apr 14 Apr 02 Jun

$18 \mathrm{Nov}$

12

Length

45

163

151

Nov 208

154

\section{Root}

Oceanic

210

100

$154 \quad 210$

Continental 240

118

$124 \quad 240$

Mediterranean 216

$126 \quad 216$

- no observation recorded 
Table 3: Correlations between mean soil and air temperatures, mean soil water potential of the preceding month and root elongation rate (RER),

\begin{tabular}{lccccccc}
\hline & Variable & \multicolumn{2}{c}{ oceanic } & \multicolumn{2}{c}{ continental } & \multicolumn{2}{c}{ Mediterranean } \\
& & $\rho$ & $\mathrm{P}$ & $\rho$ & $\mathrm{P}$ & $\rho$ & $\mathrm{P}$ \\
\hline Soil & & & & & & \\
temperature & RER & 0.61 & $<0.001^{* *}$ & 0.28 & 0.21 & -0.12 & 0.61 \\
& RMQ & 0.06 & 0.38 & -0.28 & $<0.001^{* *}$ & -0.54 & $<0.001^{* *}$ \\
Air temperature & RER & 0.48 & $0.005^{* *}$ & 0.28 & 0.21 & 0.06 & 0.78 \\
& RIQ & 0.14 & $0.04^{*}$ & -0.12 & 0.06 & -0.37 & $<0.001^{*}$ \\
& RMQ & 0.17 & 0.11 & 0.16 & 0.08 & 0.12 & 0.48 \\
Soil water & RER & -0.48 & $0.005^{* *}$ & 0.21 & 0.51 & 0.50 & $0.05^{*}$ \\
potential & RIQ & 0.08 & 0.23 & 0.13 & 0.11 & -0.01 & 0.86 \\
& RMQ & -0.16 & 0.14 & -0.66 & $<0.001^{* * *}$ & 0.06 & 0.64 \\
\hline
\end{tabular}




\section{Supplementary Material}

Figure S1: Aerial view of the three sites from Google Earth images 2016
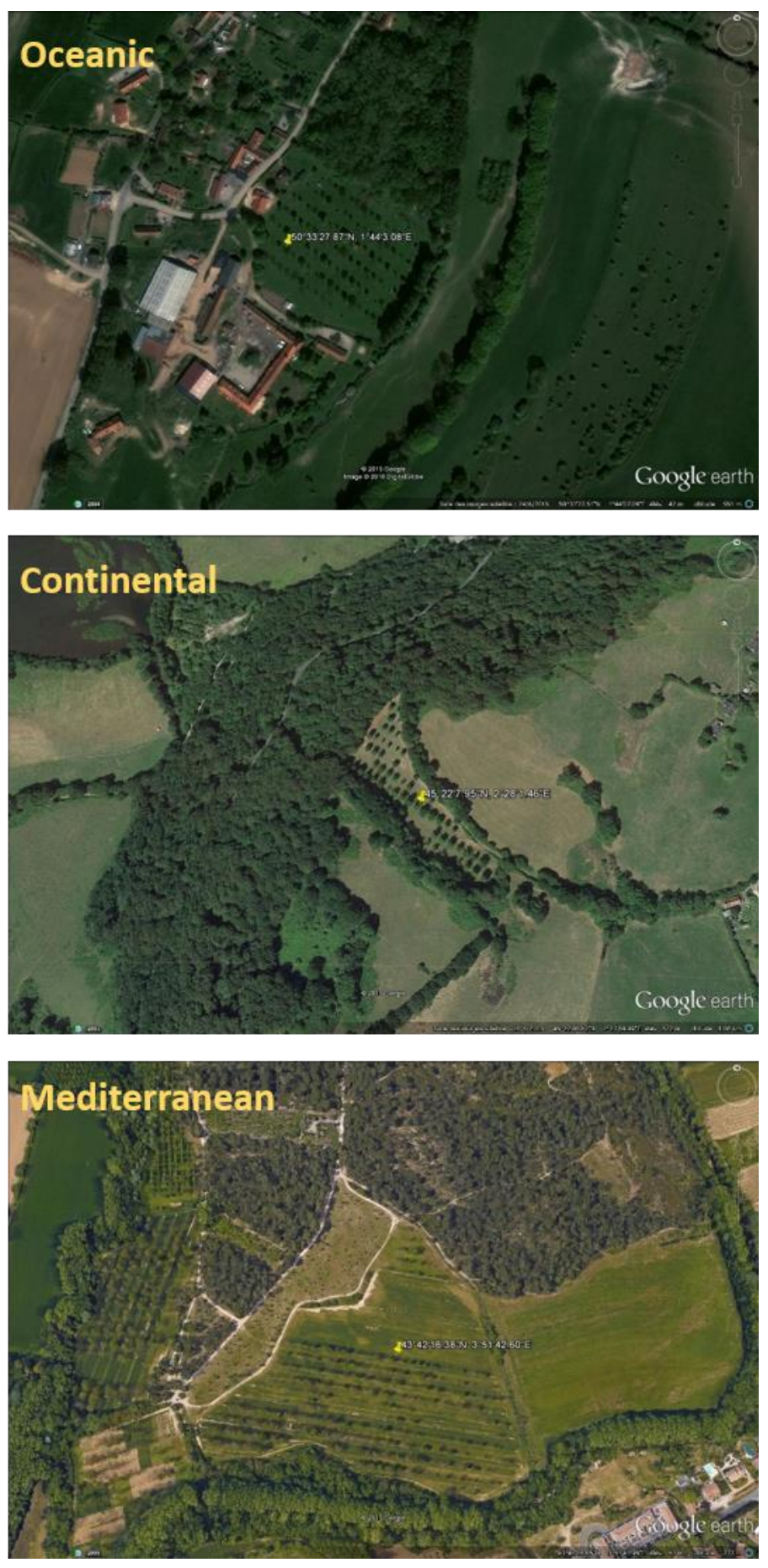
Figure S2 Geographic location of each site along the latitudinal gradient in France

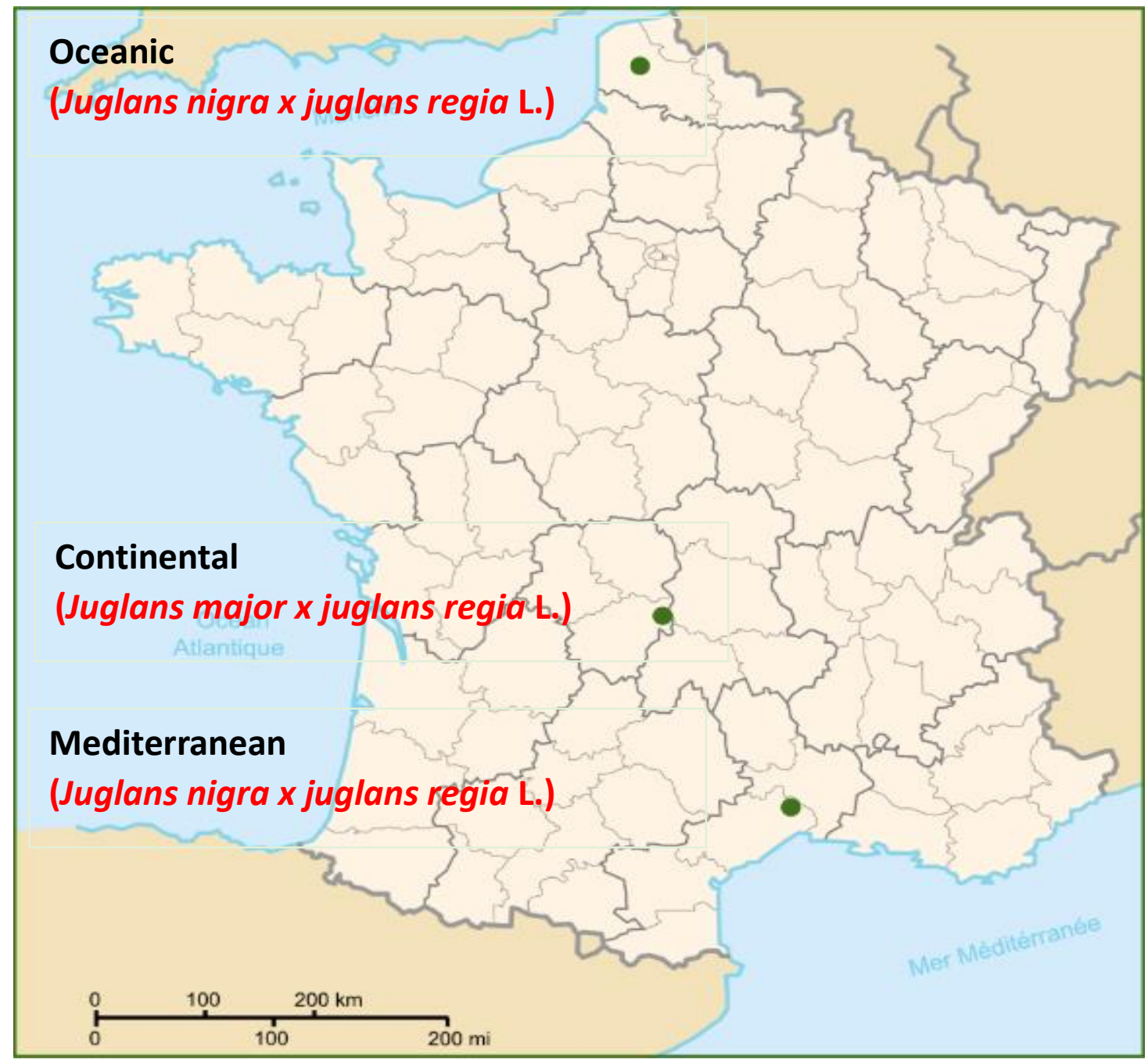




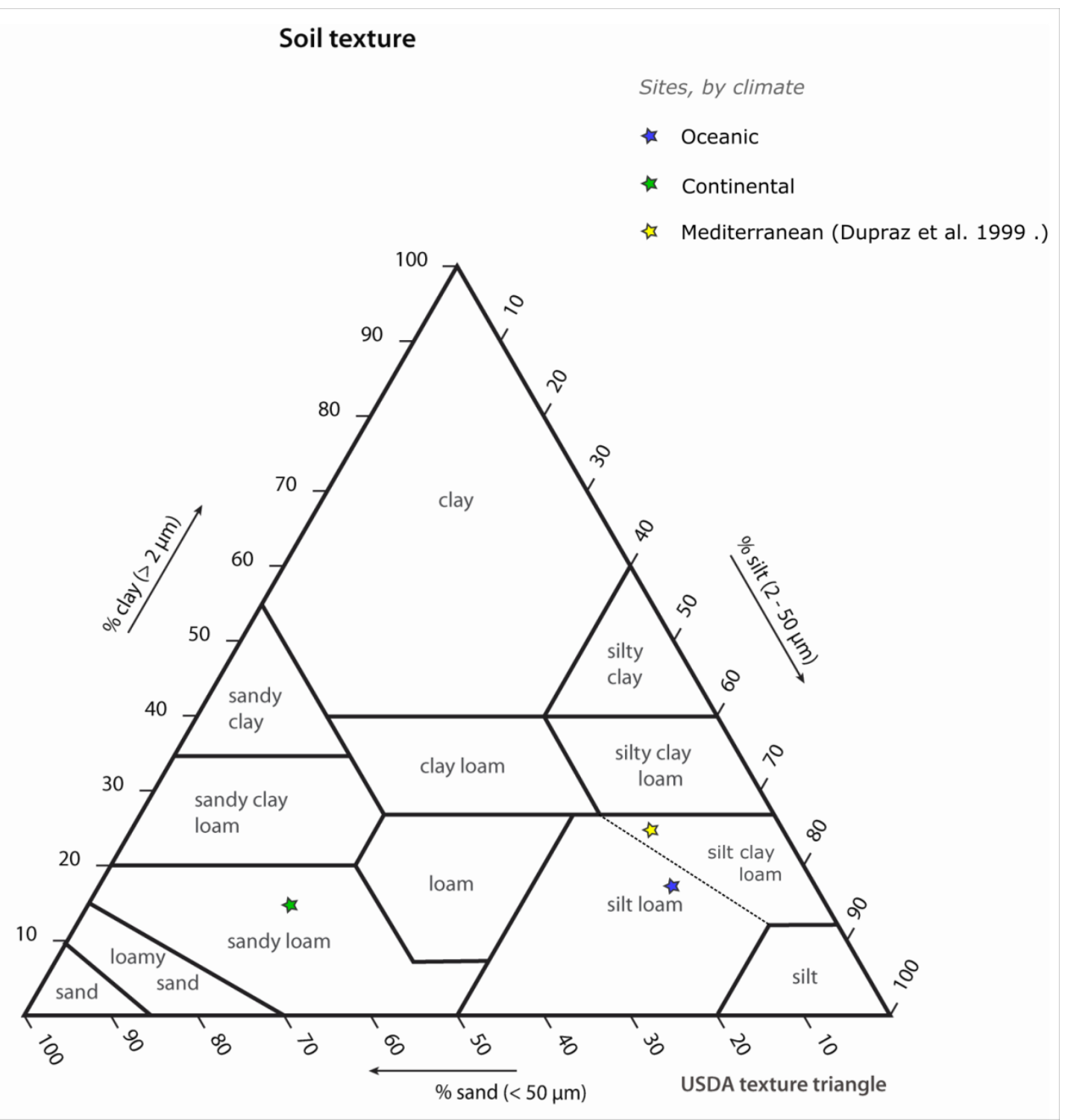

Fig S3: Soil texture at each site 
Figure S4 Trenches with rhizotrons at the continental and oceanic sites

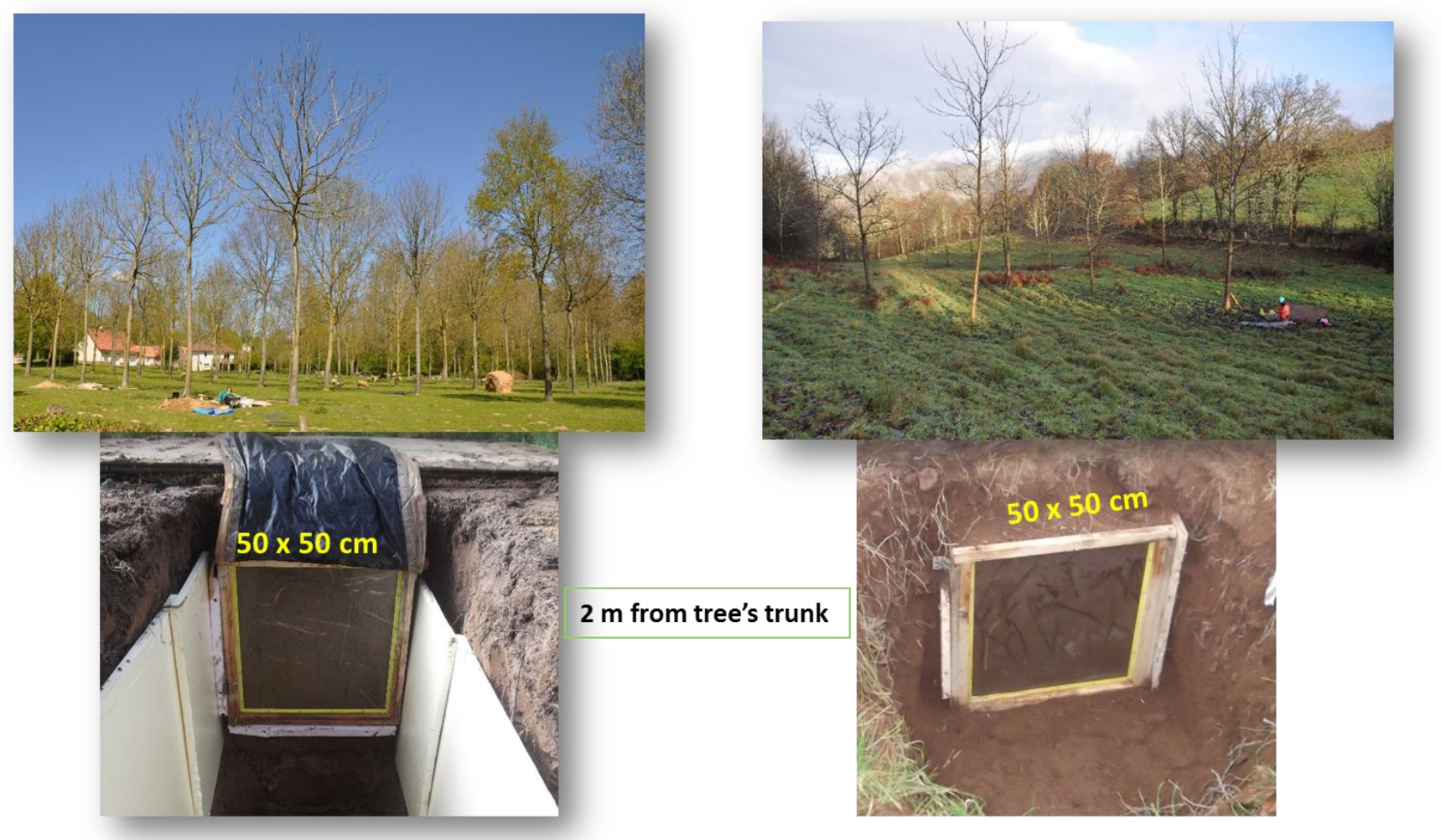


Figure S5 Trench with rhizotrons at the Mediterranean site
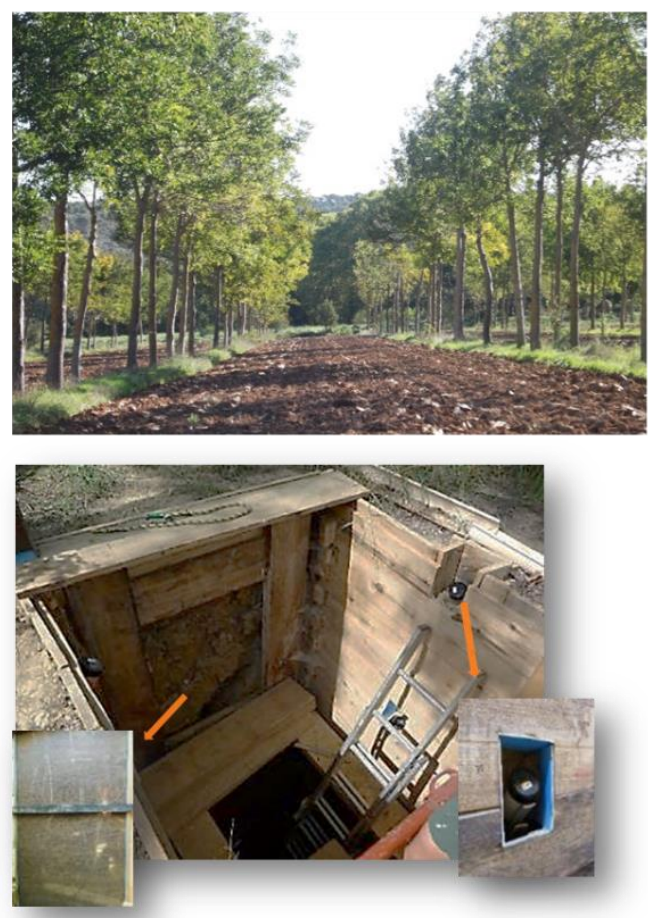
Figure S5 Techniques used to obtain images of roots in rhizotrons

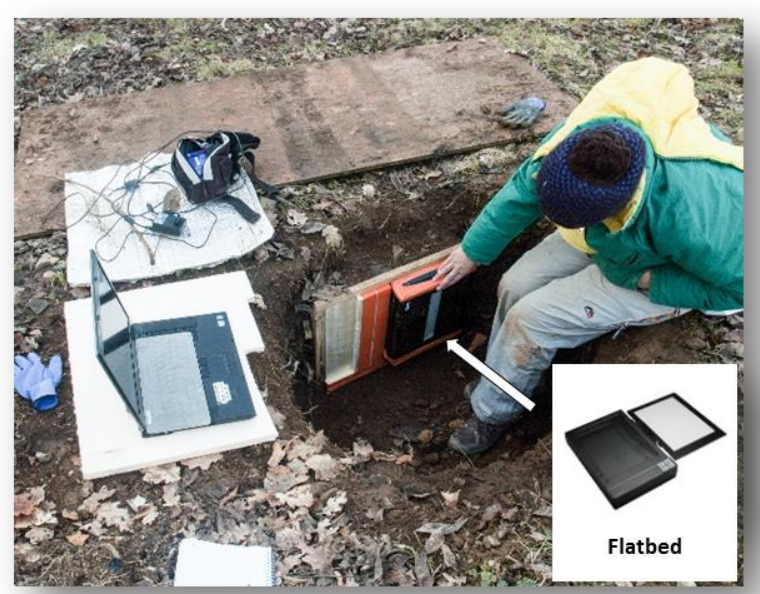

Flatbed scanner (Epson Perfection V370)

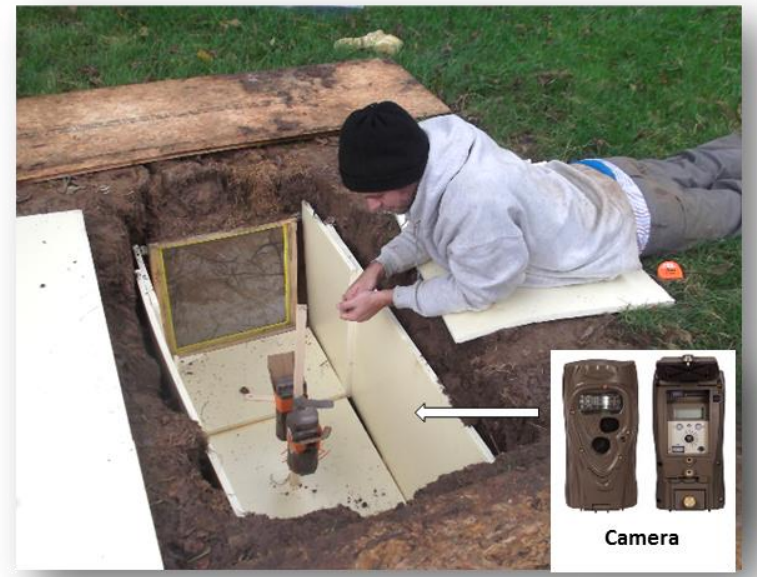

Time lapse camera (CUDDEBACK ATTACK)
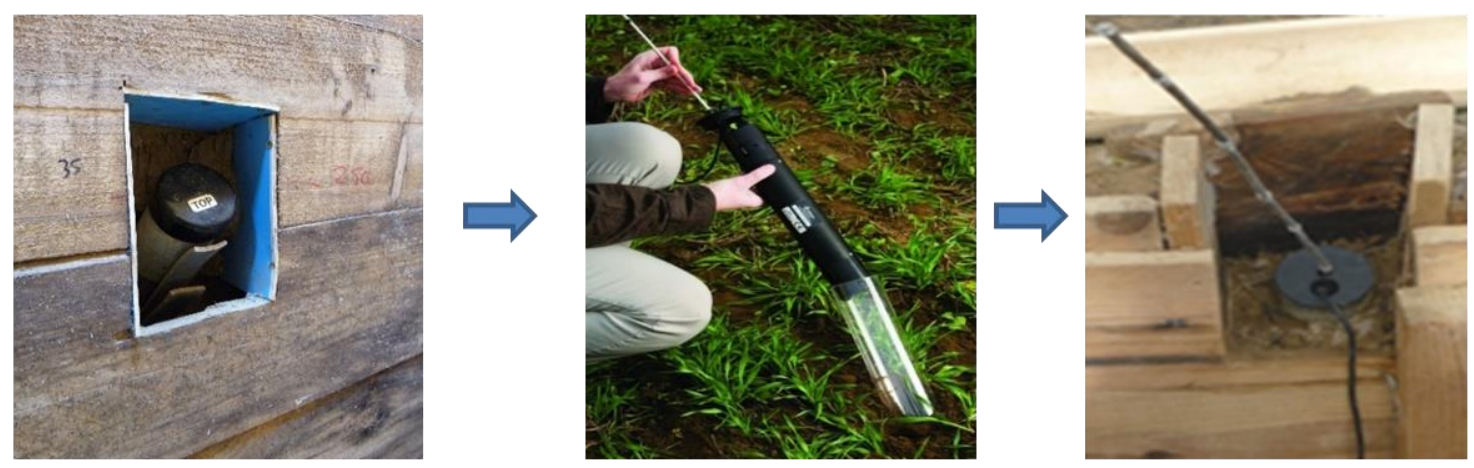

Circular scanner (Cl-600 Digital Root Imager) 